Portland State University

PDXScholar

1989

\title{
The output of compression hearing aids with a transient input signal
}

Michael Andrew Berg

Portland State University

Follow this and additional works at: https://pdxscholar.library.pdx.edu/open_access_etds

Part of the Speech Pathology and Audiology Commons Let us know how access to this document benefits you.

\section{Recommended Citation}

Berg, Michael Andrew, "The output of compression hearing aids with a transient input signal" (1989). Dissertations and Theses. Paper 3859.

https://doi.org/10.15760/etd.5743

This Thesis is brought to you for free and open access. It has been accepted for inclusion in Dissertations and Theses by an authorized administrator of PDXScholar. Please contact us if we can make this document more accessible: pdxscholar@pdx.edu. 
AN ABSTRACT OF THE THESIS OF Michael Andrew Berg for the Master of Science in Audiology presented June 27, 1989.

Title: The Output of Compression Hearing Aids With A Transient Input Signal.

APPROVED BY MEMBERS OF THE THESIS COMMITTEE:
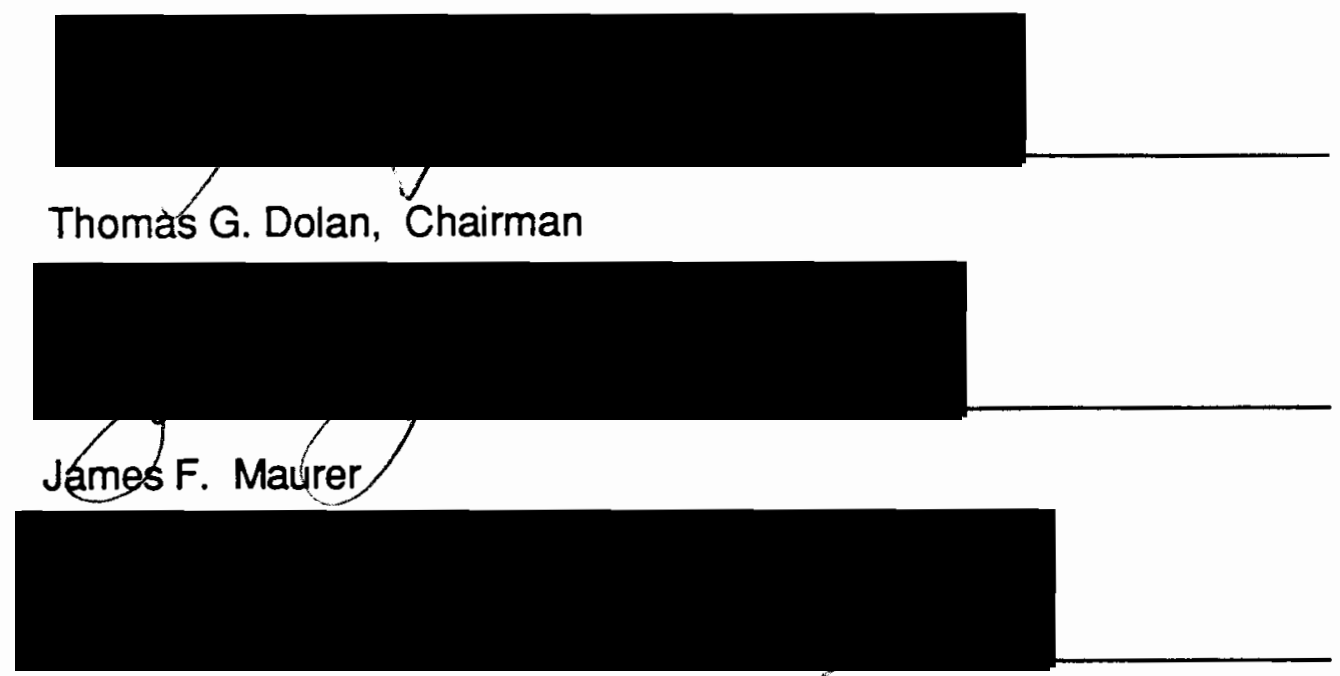

David H. Martinez

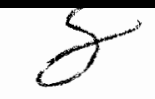

The output characteristics of five compression hearing aids in response to a transient signal were examined to determine if, the input-output function (i.e. output levels of the hearing aid as a function of input level) for a transient signal could be made to approximate that of a continuous signal, by activating the compression circuit with a second signal (activator). Input-output functions for three input compression and two output compression hearing aids were obtained in order to determine if: 1. the automatic gain control (AGC) was activated by the second signal and the transient signal output approximates that 
of a continuous tone, and 2 . if the second tone was evident in the output of the hearing aid and thereby potentially being an interfering factor in aided auditory brainstem response (ABR) measurement.

The results of this study indicate that the use of an activator tone or high pass noise is effective in reducing the output of a hearing aid in response to a transient signal in most hearing aids. However, it was not capable of reducing the output of the transient signal to a value close to that of a continuous tone with AGC full-on. Specifically, in four out of five hearing aids, the activator at one constant level reduced the amplitude of the transient signal at the output of the hearing to a value that was too low. Also, the compression was typically not activated enough when the activator level was varied with the transient signal.

An exception was found with the Unitron UE 10, where it was possible to reduce the output of the hearing aid in response to a transient signal to a level within $3 \mathrm{~dB}$ of that of a continues tone with AGC full-on. This was the case when both a high frequency tone and a high pass noise were used as activators. That is, the output for the Unitron UE 10 with a transient signal input could be made to approximate that of a continuous tone. Thus, the original goal of activating the compression circuit with a high frequency activator tone or noise was only accomplished in one of the five hearing aids, and it was only possible when the activator signal was varied with the transient input.

In conclusion, different hearing aids process transient signals differently. Also, although an extra, high frequency tone or noise can activate the compression circuit of most hearing aids, it generally does not reduce the output of the hearing aid to the desired level. Only for one hearing aid was this possible, and it required a great amount of time and instrumentation. This method therefore does not seem very promising in the clinical measurement of aided $A B R$ 's. 


\title{
THE OUTPUT OF COMPRESSION HEARING AIDS
}

WITH A TRANSIENT INPUT SIGNAL

by

MICHAEL ANDREW BERG

A thesis submitted in partial fulfillment of the requirements for the degree of

\author{
MASTER OF SCIENCE \\ in \\ SPEECH COMMUNICATION: \\ SPEECH AND HEARING SCIENCE
}

Portland State University

1989 
TO THE OFFICE OF GRADUATE STUDIES:

The members of the Committee approve the thesis of Michael A. Berg presented June 27, 1989.

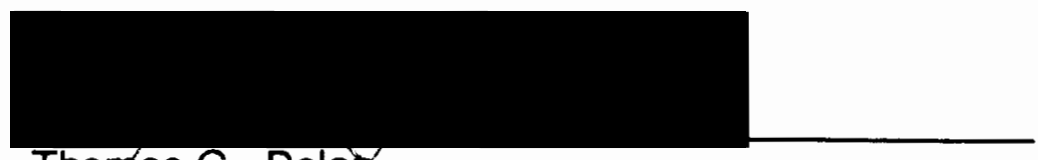

Thomas G. Dolañ
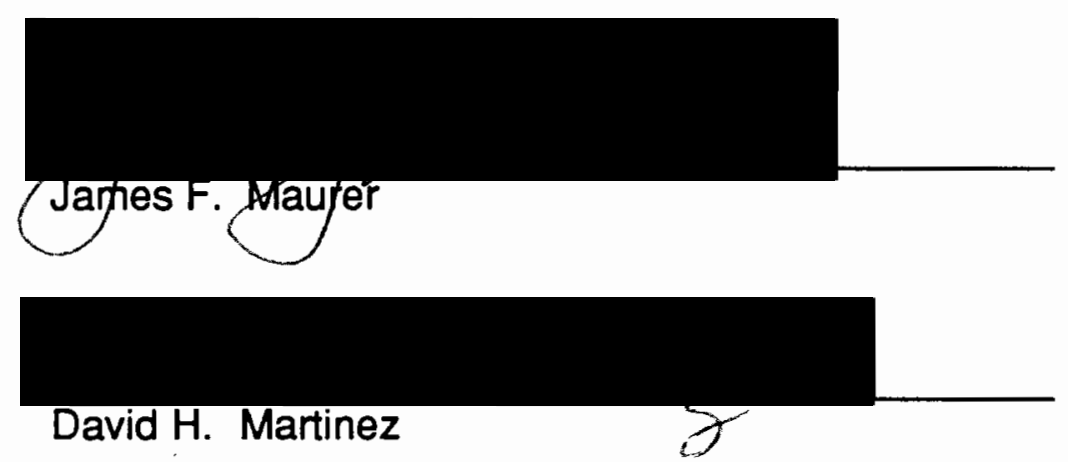

APPROVED:

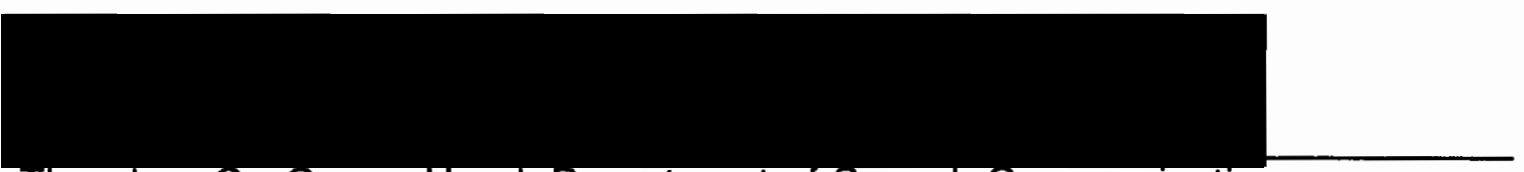

Theodore G. Grove, Head, Department of Speech Communication

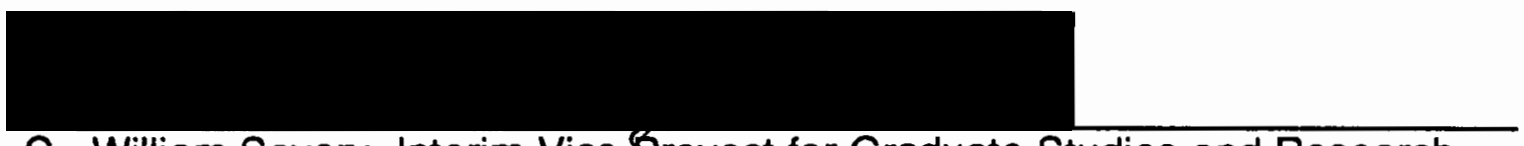

C. William Savery, Interim Vice Provost for Graduate Studies and Research 


\section{ACKNOWLEDGEMENTS}

Special thanks to Dr. Thomas G. Dolan for all of his assistance and patients during this study, and to my wife Jennifer for all of her love and support. I couldn't have done it without you! 
TABLE OF CONTENTS

Page

ACKNOWLEDGEMENTS . . . . . . . . . . . . . . iii LIST OF TABLES . . . . . . . . . . . . . . . . . . . . v v LIST OF FIGURES . . . . . . . . . . . . . . . . . . . . . . . . v vi

\section{CHAPTER}

I INTRODUCTION . . . . . . . . . . . . . . . 1

$\| \quad$ REVIEW OF LITERATURE $\ldots \ldots \ldots$

III METHODS . . . . . . . . . . . . . . . . . 12

Acoustic signals . . . . . . . . . . . . . . . 12

Instrumentation . . . . . . . . . . . . . . . . . . 14

Procedure . . . . . . . . . . . . . . . 18

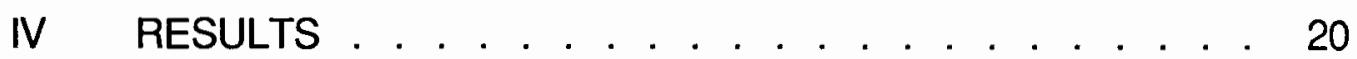

$\checkmark \quad$ DISCUSSION . . . . . . . . . . . . . 45

REFERENCES . . . . . . . . . . . . . . . . . . . . . . 48 APPENDICES

A ATTACK AND RELEASE TIME $\ldots \ldots . \ldots 50$

B PEAK EQUIVALENT CALCULATION . . . . . . . . 51 


\section{LIST OF TABLES}

TABLE

PAGE

I Hearing Aids Attack and Release Time . . . . . . . . . . . 


\section{LIST OF FIGURES}

FIGURE

PAGE

1. Graphic Representation of Attack and Release Time. . . . .

2. A Series of Time Waveforms of the Transient Signal Used as Input to the Hearing Aid . . . . . . . . . . . . . . . 13

3. Box Diagram of Instrumentation Setup. . . . . . . . . . . 15

4. Input-Output Functions for a Unitron UE 10 Hearing Aid.

Output of the Hearing Aid in dB SPL, is Plotted as a

Function of Level of a $3000 \mathrm{~Hz}$, Continuous Tone Input .

5. Input-Output Functions for a Oticon E 38 P Hearing Aid.

Output of the Hearing Aid in dB SPL, is Plotted as a

Function of Level of a $3000 \mathrm{~Hz}$, Continuous Tone Input. .

6. Input-Output Functions for a Unitron UE 10 Hearing Aid in

Response to a Transient Signal with AGC Set to the

Full-On Position (Circles) and AGC Set to Minimum

Position (Squares) . . . . . . . . . . . . . . . . .

7. Input-Output Functions for a Unitron UE 10 Hearing Aid

In Response to a $3000 \mathrm{~Hz}$ Continuous tone (Circles) and for a Transient Signal (Squares) . . . . . . . . .

8. Input-Output Functions for a Unitron UE 10 Hearing Aid in

Response to a Continuous $3000 \mathrm{~Hz}$ Tone with

AGC Set at Minimum (Circles) and the Output of the Aid

to a Transient Signal With AGC Full-On (squares) . 
9. Input-Output Function for a Oticon E 38 P Hearing Aid in

Response to a Transient Signal with AGC Set to Full-on

Position (Circles) and AGC Set to Minimum Position (Squares) . . . . . . . . . . . . . . . . . . . . . . 28

10. Input-Output Functions for an Oticon E 38 P Hearing Aid with AGC Set to Full-On, for a Continuous $3000 \mathrm{~Hz}$ Tone (Circles) and for a Transient Signal (Squares).

11. Time Waveforms of the Output of the Unitron UE 10 Hearing

Aid .

12. Amplitude of a Transient Signal at the Output of a Unitron UE 10 Hearing Aid As a Function of Activator Frequency .

13. Input-Output Functions for the Unitron UE 10, Showing the the Effect of a High Frequency Activator Tone on the Output of the Hearing Aid for a Transient Signal with AGC Full-On .

14. Input-Output Functions for the Oticon E $38 \mathrm{P}$, Showing the the Effect of a High Frequency Activator Tone on the Output of the Hearing Aid for a Transient Signal with AGC Full-On

15. Input-Output Functions for the Bernaton T86, Showing the the Effect of a High Frequency Activator Tone on the Output of the Hearing Aid for a Transient Signal with AGC Full-On . . . . . . . . . . . . . . . . . . . .

16. Input-Output Functions for the Siemens PP AGC I, Showing the the Effect of a High Frequency Activator Tone on the Output of the Hearing Aid for a Transient Signal with AGC Full-On 
17. Input-Output Functions for the Audiotone A-52S, Showing the the Effect of a High Frequency Activator Tone on the Output of the Hearing Aid for a Transient Signal with AGC Full-On . . . . . . . . . . . . . . . . . . 39

18. Input-Output Functions for the Unitron UE 10, Showing the the Effect of a High Pass Noise on the Output of the Hearing Aid for a Transient Signal with AGC Full-On . . . 42

19. Input-Output Functions for the Oticon E $38 \mathrm{P}$, Showing the the Effect of a High Pass Noise on the Output of the Hearing Aid for a Transient Signal with AGC Full-On .

20. Input-Output Functions for a Audiotone A-52S Showing the

Effect of a Variable Level High Pass Noise (Triangles) as well as A High Pass Noise at 1 Level (Squares) has on the Output of the Hearing with a Transient Signal Input . . . . . . . . . . . . . . . . . . . . . 44 


\section{CHAPTER I}

\section{INTRODUCTION}

One of the greatest challenges to an audiologist is fitting a pre-verbal child with hearing aids, with some degree of confidence. In adults with hearing loss, we use the results of many behavioral tests in prescribing hearing aids and assessing the goodness of fit (Skinner, 1988). However, in pre-verbal children and other selected groups, this behavioral information is not available to the audiologist, simply because these clients may be unable to follow instructions or perform the tasks needed to obtain this information. As a result, hearing aid selection, as well as the settings for gain, tone and compression are done largely on the basis of guess-work in this population. This is particularly unfortunate given the need for proper, early intervention during this critical time of language development. Without early intervention, of which proper hearing aid selection is an integral part of, a child will begin to fall behind in psychological, social, educational, cognitive, language and many other areas of development from the first months of life (Sanders, 1977).

One possible solution to the problem of fitting hearing aids on pre-verbal children is to use the auditory brainstem response (ABR). In the past, the ABR has been used in the diagnosis of various disorders involving the auditory pathway. It has also been used to detect hearing loss and estimate behavioral thresholds on individuals who are unable to be tested by conventional methods. This group of clients includes people with mental deficiencies, the physically handicapped and pre-verbal children. Beachaine and Gorga (1988) suggested 
that the ABR be used "to measure an evoked potential equivalent of the pure tone audiogram" along with real-ear acoustical measurements to fit hearing aids. Other authors have also used the ABR in a diagnostic role, facilitating a more accurate picture of true auditory thresholds, and thus enabling a better initial hearing aid prescription than conventional behavioral methods. (Kodera, Yamana, Yamana, \& Suzuki, 1977; Don, Eggermont and Brackman, 1979; and Mjoen, 1981).

In addition to its use as a diagnostic measure, the ABR has recently been explored as a means of prescribing and assessing the goodness of fit on hearing aids. A number of authors have attempted to assess the fit of the hearing aid and adjust the electroacoustic settings of the hearing aid on the basis of ABR responses to an aided ear. That is, the acoustic signal used to elicit the ABR is delivered to the hearing aid, which amplifies the signal and delivers it to the clients ear (Cox \& Metz, 1980; Gorga, Beauchaine and Reiland, 1987 ; Hecox, 1983; Mahoney, 1985; McPherson and Clark, 1983; Sander, 1983; Kileny, 1982; Hecox, Breuninger and Krebs, 1975; and Beauchaine, Gorga, Reiland, and Larson 1986). The above authors all differ somewhat in the approach they use for obtaining aided ABR's, but the goal is the same, and that is to normalize, via amplification, the amplitude, slope, threshold or latency of components of the ABR waveform.

One inherent problem in hearing aid prescription is that, in a certain percentage of sensory-neural hearing losses, the problem of loudness recruitment must be taken into account. That is, a certain percentage of sensoryneural losses have a reduced dynamic range, which is the area between ucomfortable loudness level and absolute threshold. For example, a clients threshold for speech may be $65 \mathrm{~dB}$ and his uncomfortable loudness level 90 $\mathrm{dB}$. This would mean that in order for a successful hearing aid fitting, more 
amplification would be needed at lower intensity levels and less at higher input levels. To accomplish this, we use hearing aids with automatic gain control (AGC). The AGC in a hearing aid is basically an output limiting device which allows an increased amount of gain for low input levels, but at the same time decreases the amount of gain for high input signals. However, in order to elicit the $A B R$, an acoustic signal with a rapid onset is required because the $A B R$ is a onset response. Consequently, transient stimuli such as clicks and tone bursts are used clinically in ABR measures (Beauchaine and Gorga, 1988).

A potential problem in measurement of the ABR in an aided ear (i.e. aided $A B R$ ) is that the transient signal may be shorter than the time it takes the AGC circuit to be activated (see figure 1 and Appendix A). The gain of the hearing aid therefore, may not be reduced as it would for a continuous tone. Thus, the output levels of AGC hearing aids for a transient signal used in ABR measurements may be higher than for a continuous stimuli. A possible solution to this problem is to activate the compression circuit during presentation of the transient signal. One way of doing this would be to present a second continuous signal during presentation of the transient signal. One potential problem with this is that the continuous tone used to activate the compression may be present in the output of the hearing aid, and this could interfere with the ABR. A possible solution is to adjust the frequency of the continuous tone to be within the frequency response of the hearing aid microphone (which may extend up to about $10 \mathrm{KHz}$ ) but above the high frequency cutoff of the receiver (typically 5-6 $\mathrm{KHz}$ ). It is possible that the second tone could activate the compression circuit of the hearing aid, while at the same time not showing up in the output of the hearing aid. This would allow us to obtain aided ABR with the AGC circuit activated. 
ENVELOPE OF INPUT SIGNAL

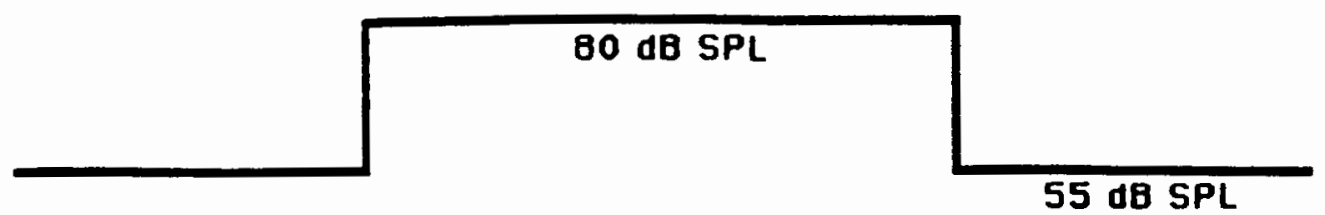

$1 \mathrm{KHz}$

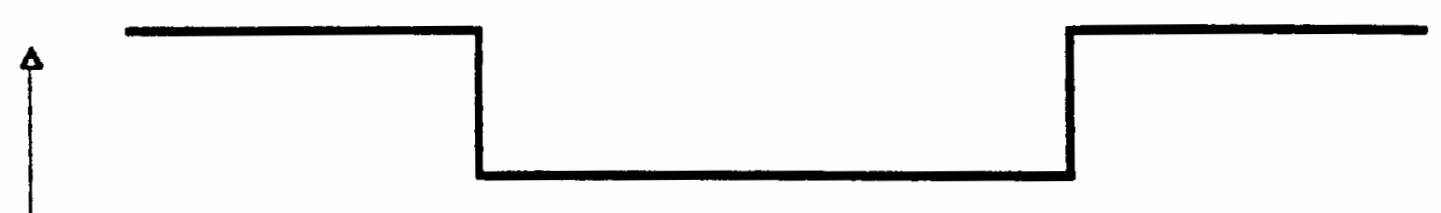

A

M

$\mathbf{P}$

L

I

T

U

D

E
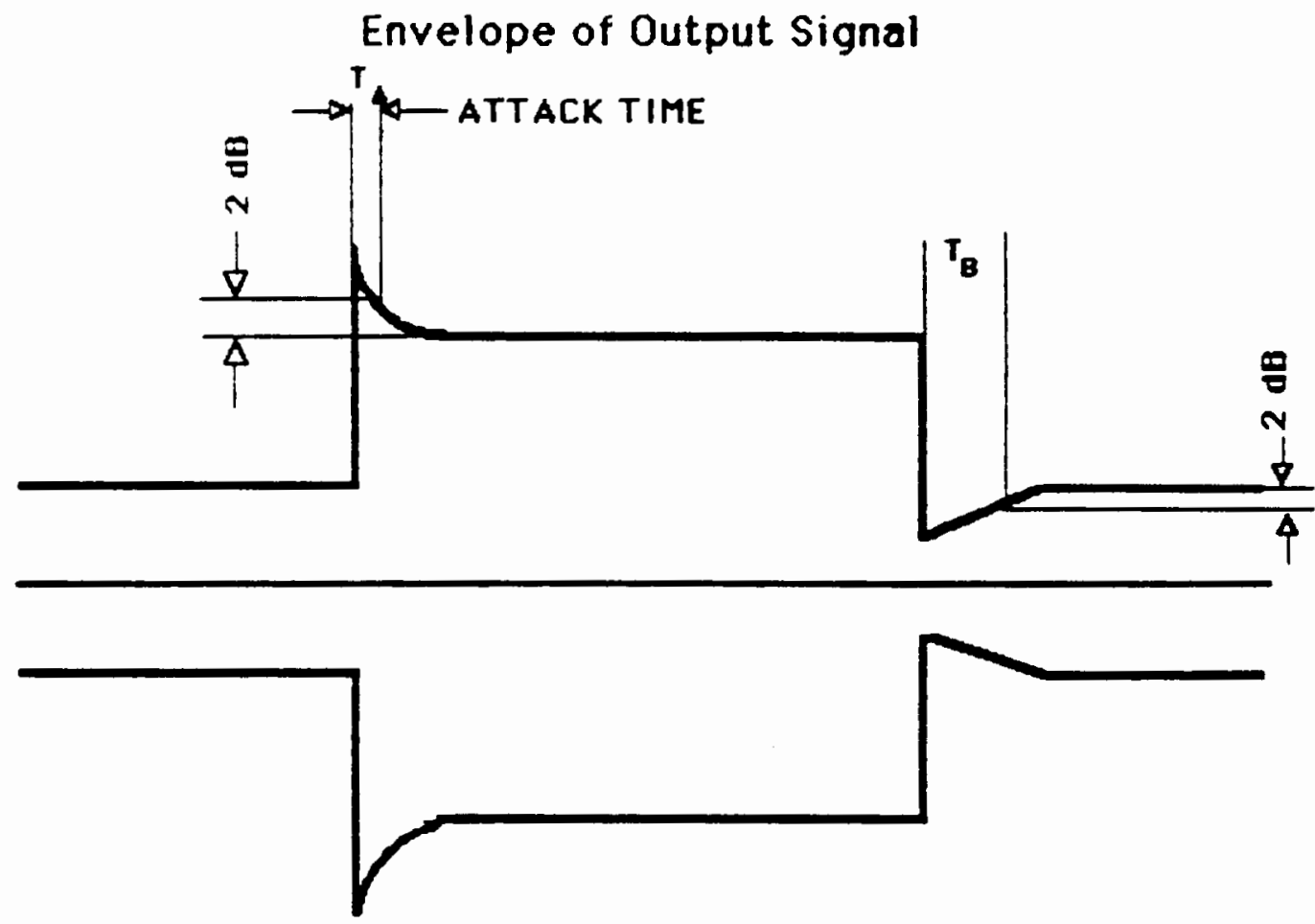

Time

FIGURE 1. Graphic representation of attack and release time. 
The purpose of this study was to determine if this method is feasible. Specifically, this study is an attempt to determine if the input-output function (i.e. output levels of the hearing aid as a function of input level) for a transient signal could be made to approximate that of a continuous signal by activating the compression circuit with a second signal. The level and frequency of the AGC activating tone were varied. We then examined the input-output function of the hearing aid to determine if: 1 . the AGC was activated and the transient signal output approximates that of a continuous tone, and 2. if the second tone is visible in the output of the hearing aid, and thus, potentially being an interfering factor in ABR measurement. 


\section{CHAPTER II}

\section{REVIEW OF LITERATURE}

Use of the ABR as a diagnostic tool has long been accepted in the field of audiology. However, its use in hearing aid evaluation has only recently been studied. Mokotoff \& Krebs (1976) were among the first to suggest that the aided ABR has potential as a means of hearing aid fitting and evaluation. In 1983 , McPherson and Clark found that a person with an artificially induced conductive hearing loss, had a most comfortable listening level (MCL) to a click signal that corresponds to a wave V latency of 6.5 milliseconds $(\mathrm{ms})$ and the UCL to the same signal occurs at $5.3 \mathrm{~ms}$. Thus, the idea is to keep the aided ABR wave $V$ latency between 5.3 and 6.5 ms by means of the hearing aids compression circuit to ensure a good fit. Kileny (1982) presented four case studies using the $A B R$ as a means of selecting hearing aids, comparing unaided VS aided responses. He indicated that his method of selection was feasible. However, he did point out two possible problems with this method: "the possible contamination of the ABR waveform by electromagnetic artifacts caused by ringing of the hearing aid" and feedback problems. Cox and Metz (1980) used a hearing aid with four frequency response settings and found a high correlation between the setting that produced the best speech discrimination score and the setting that produced the shortest wave $V$ latency with 1000 and $2000 \mathrm{~Hz}$ tone pips as the ABR signal.

Beauchaine, Gorga, Reiland \& Larson (1986) used aided ABR's and a single hearing aid with three frequency response settings. They attempted to 
estimate the amount of gain the hearing aid was producing by calculating "shifts in Wave $\mathrm{V}$ thresholds, shifts in Wave $\mathrm{V}$ latency-level functions, acoustic-reflex measurements, coupler gain measurements, and measurements of functional gain." The study indicated that the ABR is not a good indicator of the amount of low frequency gain obtained by a given hearing aid. However, they did indicate that the aided $A B R$ is capable of estimating the amount high frequency gain obtained by a given hearing aid.

Kiessling (1982) used a mathematical model based on wave $V$ amplitude rather than latency for projecting proper hearing aid fitting and on the basis of the mathematical model compression and gain requirements were determined.

Gorga, Beauchaine and Reiland (1987) explored the effects of stimulus rate and attack and release times on a $2000 \mathrm{~Hz}$ tone burst. They expressed concern that each hearing aid seemed to interact differently with the stimuli, thus limiting it's use in the selection of hearing aids.

Sanders (1983) used the slow brainstem response (SN10) and found that it was a reliable estimator of behavioral threshold (within $10 \mathrm{~dB}$ ) in $79 \%$ of normal hearing subjects. He also found favorable responses on four hearing impaired subjects with aided SN10, in that he was able to, on average, come within $4.75 \mathrm{~dB}$ of behavioral thresholds.

Hecox (1983) felt the way to approach hearing aid fitting problems was to make the latency intensity function (the latency of the ABR wave $V$ as a function of signal intensity) in hearing impaired individuals, similar to those of normals, by means of amplification. He also made four hypothesis 1. "The greater the displacement of the latency-intensity function from normal the larger the gain requirements..." 2. "The steeper the latency-intensity function the less likely that linear amplification will prove superior to compression amplification..." $3 . . . "$ there is no advantage to amplifying speech to a level greater than 
conversational levels... 4. "Hearing aids are unlikely to help those "...with pure central involvement"... Hecox's idea of normalizing the latency intensity function is easily accomplished with conductive losses since it is simply a matter of overcoming the amount of conductive loss that is present without changing the slope of the latency intensity-function. That is, the latency-intensity function in a conductive loss is similar to that of a normal ear except for the fact that it is shifted to the right along the abscissa. Normalizing the function is simply a matter of providing enough gain to shift the function to the left. For example, if a person has a $30 \mathrm{~dB}$ conductive loss, it would take a $90 \mathrm{~dB}$ signal to bring wave $V$ latency to the same point a $60 \mathrm{~dB}$ signal does in normal ears. In a certain percentage of sensori-neural losses, recruitment may increase the slope of the latency intensity function. This is due to the fact that at ABR thresholds a cochlear impaired ear may show latencies that are longer than normal. However, at higher signal levels ABR latencies may be equal to those of normal individuals. This would mean that more amplification would be needed at lower intensity levels and less at higher input levels. For example, if exactly a $90 \mathrm{~dB}$ output is needed with a hearing aid with a $55 \mathrm{~dB}$ input, $35 \mathrm{~dB}$ of gain would be needed, whereas with a $75 \mathrm{~dB}$ input only $15 \mathrm{~dB}$ of gain is needed. To accomplish this, we use hearing aids with AGC. The AGC in a hearing aid is basically an output limiting device which allows an increased amount of gain for stimuli with low input levels but at the same time decreases the amount of gain for high input signal levels. As mentioned earlier, a potential problem is that the transient signal may be shorter than the the time it takes the AGC circuit to be activated. Thus, the output may not be reduced as it would for a continuous tone. Therefore, the normal latency-intensity function as described by Hecox (1983) could not be approximated with a transient signal used in ABR. 
As exciting and appealing as using the ABR in hearing aid fitting may sound, there are many problems with it. To start with, the ABR elicited with a click is attributed to the middle and high frequencies $(1000-4000 \mathrm{~Hz})$ (Coates and Martin, 1977). Use of the click therefore does not allow for accurate assessment of the low frequencies in an aided ABR hearing aid evaluation (Beauchaine And Gorga, 1988).

Kileny (1982) stated that ..."one potential problem area associated with the aided ABR's: the contamination of recorded electrophysiological potentials by electromagnetic artifacts originating from prolonged "ringing" of the hearing aid by transients utilized as stimuli." He also mentioned the possibility of "excessive acoustic feedback" and the changes in temporal as well as the frequency spectrum caused by the hearing aid. Other authors have also indicated that hearing aids may alter the transient signal used in ABR, effecting temporal, frequency, spectral, polarity, phase, latency and amplitude, (Weber et al, 1981; Hall and Ruth, 1985; and Mahoney,1985). These changes in the ABR waveform then could change the actual $A B R$ waveforms amplitude, latency and morphology. Another way of looking at this, is that. each individual hearing aid acts like an acoustical filter and changes the ABR signal in its own unique way.

Another factor mentioned by Mahoney (1985) is that a number of hearing aids release an electronic radiation that makes it very difficult to measure $A B R$ wave-forms, although he did indicate that with proper electrode impedance this problem can be overcome. The basic premise behind aided ABR's is to accurately assess how the hearing aid is able to normalize the ABR waveform. In doing so, many different hearing aids may be tried, or a single hearing aid may be tried while manipulating various settings ie.. tone control, compression, MPO etc. The hearing aid that normalizes the ABR waveform to the greatest degree would presumably be the one chosen. Obviously, a problem arises 
when the ABR signal is changed dramatically by the hearing aid, as mentioned above. However, an even greater problem arises when speaking of how the compression system of a hearing aid reacts to the transient ABR signal.

As mentioned previously, the compression system is an output limiting device which allows for an increase in the amount of gain at low input levels, but at the same time decreases the amount of gain at high input levels. This system is used mainly with sensori-neural hearing losses that demonstrate loudness recruitment and with those individuals with low tolerance levels. The AGC system has proven to be very successful in fitting hearing aid users with these particular problems (recruitment and low tolerance) (Schiff \& Sandlin 1982). It would then only seem appropriate to incorporate the AGC system into aided $A B R$ measurement. However, as indicated above, a hearing aid with a compression system cannot be evaluated when the compression is not activated by the transient ABR signal being used. In 1987 Gorga, Beauchaine \& Reiland stated " ...the rapid stimulus onsets that are needed to elicit an ABR might be so brief that the compression circuits of hearing aids would be incapable of responding with sufficient speed to reduce their outputs for such stimuli...". Yet at the same time, other researchers such as Hecox (1983) and Mahoney (1985) indicate that the compression systems are in fact activated by the ABR stimulus and can be used as a means of adjustment to normalize wave V latency-intensity functions as in Hecox's case. Beauchaine and Gorga (1988) give further evidence that the compression circuit is not activated ..."We would predict that the onset and steady-state responses would agree if the aid's circuitry was unable to return to its pre-stimulus state during the interstimulus interval (ISI). Thus, if the release time (tr) is longer than the ISI, the aid should remain in compression between stimuli. Furthermore, its onset and steady-state responses should be similar...". Other authors such as Kiessling (1982) and 
Stecker (1982) also confirm the problem of inactivation of the compression circuit while presenting a transient signal such as used in the recording of the ABR. Beauchaine and Gorga (1988) also indicate a connection between ABR stimulus rate and agreement with onset VS steady state responses. Their study consisted of comparing a steady state response to that of a $2000 \mathrm{~Hz}$ tone burst used in ABR testing. Results indicate that the faster the repetition rate the closer the onset and steady state responses are. They used 1, 30 and 50 repetitions per second, and found that the closest agreement was between a steady state response and the 50 burst per second tone burst.

The problem of activating the compression circuit with the signal used in ABR testing is a critical step if accurate assessment of hearing aid fit are to be made on the basis of aided ABR testing. To date, some question still remains as to whether or not the compression is activated by the brief ABR stimulus. At best, only certain hearing aids are capable of activating their compression circuits to this signal, and then only under certain and varying conditions, such as repetition rate, temporal aspects of the transient signal and frequency.

To date, no detailed study has made an attempt to find a technique which would place hearing aids into compression, allowing for the normalization of the ABR latency intensity as described by Hecox (1983). This study will attempt to do exactly this by exploring the use of an extra (activating) tone and noise to activate the compression circuit of various hearing aids. The effect of various combinations of frequency and amplitude of the activating tone on the inputoutput function for a click stimulus will be examined. 


\section{CHAPTER III}

\section{METHODS}

The output level of three hearing aids with input compression circuits and two with output compression were determined as a function of the input level of a continuous tone and a transient signal. For the transient signals, this was accomplished under conditions of: 1 . the transient signal alone as input, 2 . the transient signal and a high frequency tone as input, 3. the transient signal and a high pass noise as input, and 4. the transient signal and a low frequency noise or tone as input.

\section{ACOUSTIC SIGNALS}

The transient signal used as input to the hearing aids consisted of one cycle of a $3000 \mathrm{~Hz}$ tone. Measured acoustically, this signal has a rise time of $.083 \mathrm{~ms}$ and a total duration of $.33 \mathrm{~ms}$. The waveform of the acoustic signal is depicted in the top waveform in Figure 2. The transient signals were presented at a rate of 20 per second which is similar to the rate used for measuring ABR's. The signals were measured in peak equivalent level. That is, the amplitude of the transient signal is taken as equivalent to the sound pressure level (re $20 \mathrm{u}$ $\mathrm{Pa}$ ) of a continuous tone having the same peak-to-peak amplitude. (see appendix $\mathrm{B}$ for more detail). 

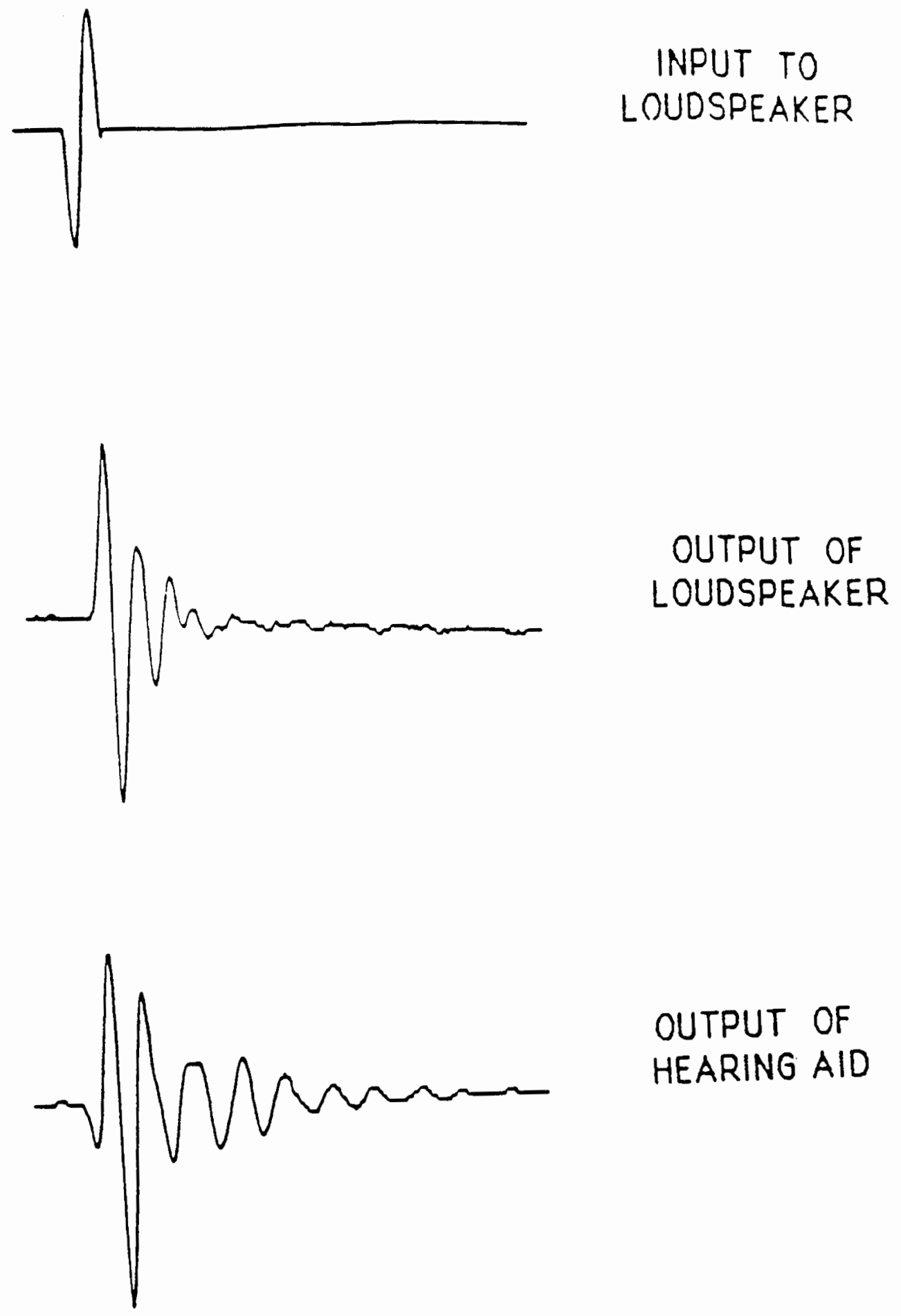

TIME

EIGURE2. A series of time waveforms of the transient signal used as input to the hearing aid. the top waveform is one cycle of a $3000 \mathrm{~Hz}$ sinusoidal voltage that was the input to the loudspeaker of the hearing aid test box. The middle plot is the output of the loudspeaker (input to aid) and the bottom plot is the output of the Unitron UE 10 Hearing aid. 
Three different types of activating signals (i.e., acoustic signal used to activate compression while transient stimuli were being presented) were used:

1. a continuous pure tone ranging in frequency from $7-8 \mathrm{KHz}, 2$. a low pass noise with a nominal high frequency cutoff of $500 \mathrm{~Hz}$ and a cutoff slope of approximately $96 \mathrm{~dB}$ per octave, and 3. a high pass noise with a low frequency cutoff of 7-8 KHz and a cutoff slope of approximately $96 \mathrm{~dB}$ per octave.

\section{INSTRUMENTATION}

Prior to the experimental procedure, each hearing aid was electroacoustically evaluated by means of a Fonix 6500 hearing aid test box to insure proper hearing aid function and accordance with ANSI S3.22-1982 standard for compression hearing aids. The Fonix test box was also used to set the volume control of each hearing aid to a reference test position (ANSI 1982). For the experimental procedure, behind-the-ear type aids were attached to an HA-2 coupler. Sound in the 2 cc coupler was transduced by means of a one inch condenser microphone (B \& $K$ type 4132 ) calibrated by means of a B \& K 4220 piston phone. The microphone was connected to a B \& K type 2203 sound level meter. Output of the sound level meter was routed to a digital storage oscilloscope (Iwatsu SS-5802), which allowed measurement of the peak-to-peak output voltage of the hearing aid. The one cycle transient signal was generated by a Moduler Instruments signal generator system. This system controlled the attenuation, phase, duration and repetition rate (20 per sec) for the 1 cycle signal. The transient signal was routed from the signal generator to the external input of the $B \& K$ hearing aid test box and delivered via the test box loudspeaker. Attenuation of the transient signal after its initial setting on the Moduler Instruments system was accomplished by means of the B \& $K$ hearing 
aid test box attenuation system. Figure 3 shows a block diagram of the instrumentation used in this study.

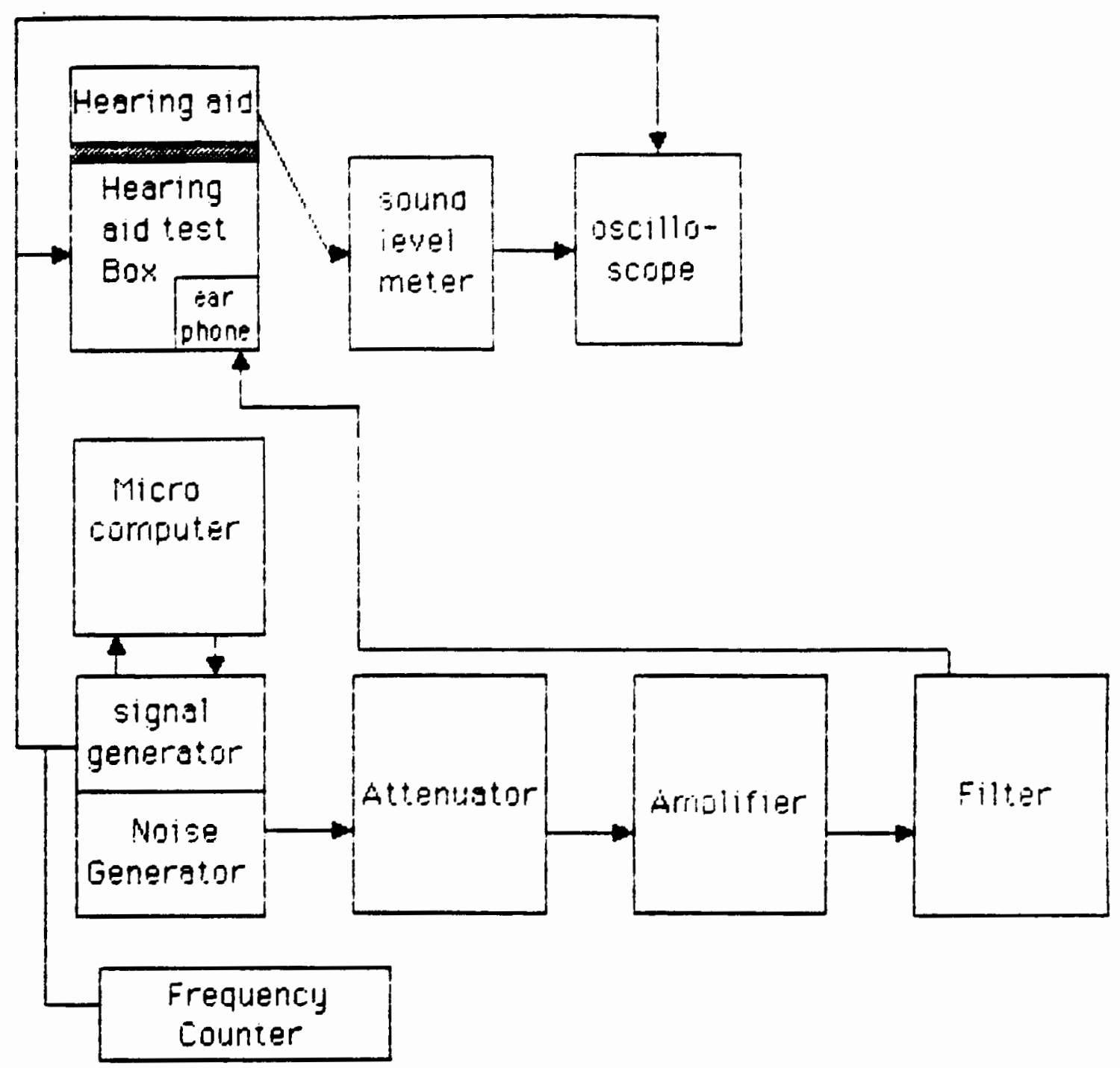

Flgupe 3. Bo\% diagram of instrumentation set up. 
The low and high pass noise used to activate the hearing aid compression circuit was generated by the by a Moduler Instruments system. The noise was routed to a Leader LAT-45 attenuator, amplified by a NAD 2240 stereo amplifier and filtered by two channels of two Krohn-Hite filters and transduced by means of a Realistic Pro-60 earphone that was placed about 3 $\mathrm{cm}$ from the microphone of the hearing aid inside the $B \& \mathrm{~K}$ hearing aid test box.

The high frequency tone was generated by a signal generator, attenuated by Leader LAT attenuator, amplified via an NAD 2240 stereo amplifier and led to the Realistic earphone placed in the hearing aid test box. The frequency of the tone was monitored by means of a Weston Schlumberger 1252 frequency counter. As stated above, the transient signal was routed directly to the hearing aid test box loudspeaker. Thus, the transient and activator signals (high pass noise, low pass noise and high frequency tone) were produced by a separate transducers. This was done to eliminate any electrical interaction between the two signals.

Three input compression hearing aids and two output compression hearing aids from different manufacturers were tested with the volume control set to the reference test position that is established with the compression off or set to minimum. This position is not in accordance with ANSI S3.33-1982 for measurement of compression hearing aids. However, the position was used because it represents a more accurate estimate of actual user gain than does the volume control full on, as recommended by ANSI S 3.33-1982. Each hearing aid was then evaluated under the conditions stated above. Table I summanizes the types of hearing aids and their attack and release times. 
TABLE I

\section{HEARING AIDS ATTACK AND RELEASE TIME}

Hearingaid Compression Attacktime $\frac{\text { Belease time }}{\text { Specs/Actual }}$

Unitron UE $10 \quad$ Input $<10 \mathrm{~ms} / 10 \mathrm{~ms} \quad 40 \mathrm{~ms} / 47 \mathrm{~ms}$

Siemens 234D Input $\quad$ /3ms $\quad / 10 \mathrm{~ms}$

PP AGC I

bernafon T $86 \quad$ Input $\quad 12 \mathrm{~ms} / 5 \mathrm{~ms} \quad 80 \mathrm{~ms} / 52 \mathrm{~ms}$

Oticon E $38 \mathrm{P} \quad$ Output $\quad 4 \mathrm{~ms} / 6 \mathrm{~ms} \quad 40-50 \mathrm{~ms} / 34 \mathrm{~ms}$

Audiotone A52S Output $\quad 10 \mathrm{~ms} / 5 \mathrm{~ms} \quad 15 \mathrm{~ms} / 51 \mathrm{~ms}$ 


\section{PROCEDURE}

Input-output functions were generated for three input compression and two output type hearing aids from five manufacturers. The volume control of each aid was set to reference test position ANSI S 3.33-1982 determined while the compression was switched off, or on minimum. For each hearing aid, inputoutput functions were obtained under the following test conditions; 1 . with a continuous $3000 \mathrm{~Hz}$ tone as input, and compression switched off or to minimum; 2. a continuous $3000 \mathrm{~Hz}$ tone input with compression full on; 3. one cycle of a $3000 \mathrm{~Hz}$ tone presented in quiet with a) compression off or set to minimum, and b) compression full-on; 4. one cycle of a $3000 \mathrm{~Hz}$ tone presented with a continuous, high frequency tone; and 5 . one cycle of a $3000 \mathrm{~Hz}$ tone presented with a) a low pass noise background, and b) a high pass noise background. The transient, 1 cycle signal was presented at a rate of 20 signals per second.

The input output functions were generated by increasing the input signal in $5 \mathrm{~dB}$ steps from 50-90 dB SPL input in all conditions. The level of the high frequency activating tone or noise was set to one constant level or was varied in $5 \mathrm{~dB}$ steps with the transient signal. In the former case, the activator level was determined by presenting the one cycle signal at the highest input level (90 dB) with compression full on. The level of the activator tone was then adjusted so that the amplitude of the transient signal at the output of the hearing aid was equal to the amplitude of the continuous $3000 \mathrm{~Hz}$ tone with a $90 \mathrm{~dB}$ SPL input with compression full-on. A second way of adjusting the activating tone was simply to start with the activating tone at the same level as above and as the one cycle transient signal is lowered the level of the activating tone is lowered with it in $5 \mathrm{~dB}$ steps. 
The frequency of the high frequency activating tone was determined by presenting the activating tone in conjunction with the transient signal. The frequency was set to a value which decreased the amplitude of the transient signal (activated compression) but at the same time did not show up in the output of the hearing aid. The cutoff frequency of the high and low pass noise was set in a step by step fashion, specifically, it was varied from $6-10 \mathrm{KHz}$ for the high and from $.1-1 \mathrm{KHz}$ for the low pass noise. 


\section{CHAPTER IV}

\section{RESULTS}

Figure 2 shows a series of time waveforms of the transient signal used as the input to the hearing aids. These waveforms were recorded by means of a Rockland 5840 A FFT spectrum analyzer and a Graphtec MP 2000 X-Y plotter. The top waveform is one cycle of a $3000 \mathrm{~Hz}$ sinusoidal voltage that was the input to the loudspeaker of the hearing aid test box. The second plot in the sequence shows the same signal transduced by the loudspeaker in the hearing aid test box. That is, this is the input waveform to the hearing aid. The third plot in the sequence is the output of a Unitron UE 10 hearing aid with the transient signal as input. The second and third plots were obtained by recording the output of a B \& K 2203 sound level meter with a B \& K type 41321 inch condenser microphone. The output of the sound level meter was recorded by means of the Rockland spectrum analyzer and then plotted. This figure shows that transduction of the transient by the loudspeaker causes the transient signal to become longer in duration. Specifically, the duration of the transient increases from .37 to about $1 \mathrm{~ms}$ when it is transduced by the speaker, and to about $2.3 \mathrm{~ms}$ when it is transduced by the hearing aid. This figure also shows that the onset phase of the original transient signal is reversed by the loudspeaker. That is, the original input began with a rarefaction phase, but the output of the loudspeaker begins with a condensation phase. This demonstrates that the transducers as well as hearing aids may alter the temporal as well as phase characteristics of the signals used in ABR 
measurement. This point has been raised by a number of authors (Weber et al, 1981; Stecker, 1981; Hall and Ruth, 1985; Mahoney, 1985; and Kileny, 1982). However, as much as the transient signal is changed by the loudspeaker and hearing aid, it still has a very brief onset, and as noted earlier, the auditory brainstem response is elicited by the initial portion of this waveform (Beauchaine and Gorga, 1988). This would suggest that the changes to the transient signal probably have little effect on the actual ABR results.

Figure 4 shows the output in dB SPL (re $20 \mathrm{u}$ Pa) of an input compression hearing aid (Unitron UE 10) as a function of level of a continuous $3000 \mathrm{~Hz}$ tone input. Input-output functions are shown for the AGC at its minimum setting and with AGC full on. Similarly, Figure 5 illustrates the output in $\mathrm{dB}$ SPL of an output compression hearing aid (Oticon E $38 \mathrm{P}$ ) as a function of level of a continuous $3000 \mathrm{~Hz}$ tone input. Again, input-output functions are shown for the AGC at its minimum setting and with AGC full on. These two figures illustrate how the input and output compression systems in hearing aids are able to reduce or limit the output of continuous or steady state signals. This is illustrated in Figure 5 where the knee in the curve is reached at $60 \mathrm{~dB}$ input or $112 \mathrm{~dB}$ output for the AGC full-on condition and the slope becomes less steep after this initial onset of the compression system. This indicates that beyond a certain input level, the gain is reduced by increasing amounts. However, the slope of the curve for the AGC minimum condition continues to be very steep and does not reach its kneepoint until an input of $80 \mathrm{~dB}$. Thus, the gain remains constant up to an input of $80 \mathrm{~dB}$ or $128 \mathrm{~dB}$ output. The kneepoint at $128 \mathrm{~dB}$ output is probably due to saturation of the aid rather than the activation of the compression system at this high level. The compression is responsible for a 15 $d B$ reduction in output at input levels of $75 \mathrm{~dB}-90 \mathrm{~dB}$. 


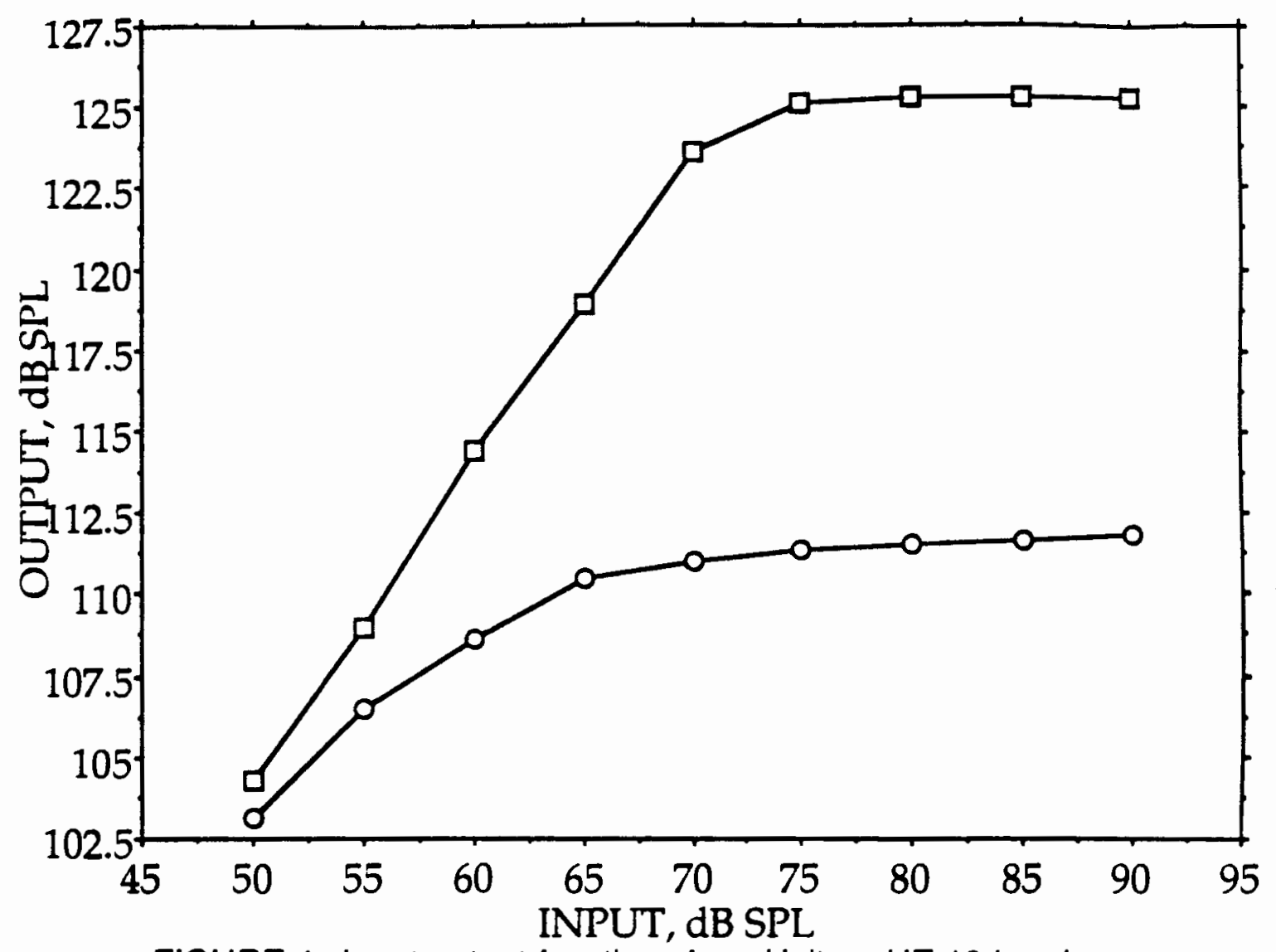

FIGURE 4. Input-output functions for a Unitron UE 10 hearing aid. Output of the hearing aid in $\mathrm{CB}$ SPL, is plotted as a function of level of a $3000 \mathrm{~Hz}$, continuous tone input. Curves are shown for AGC set to the full-on position (circles) and AGC set to minimum position (squares). 


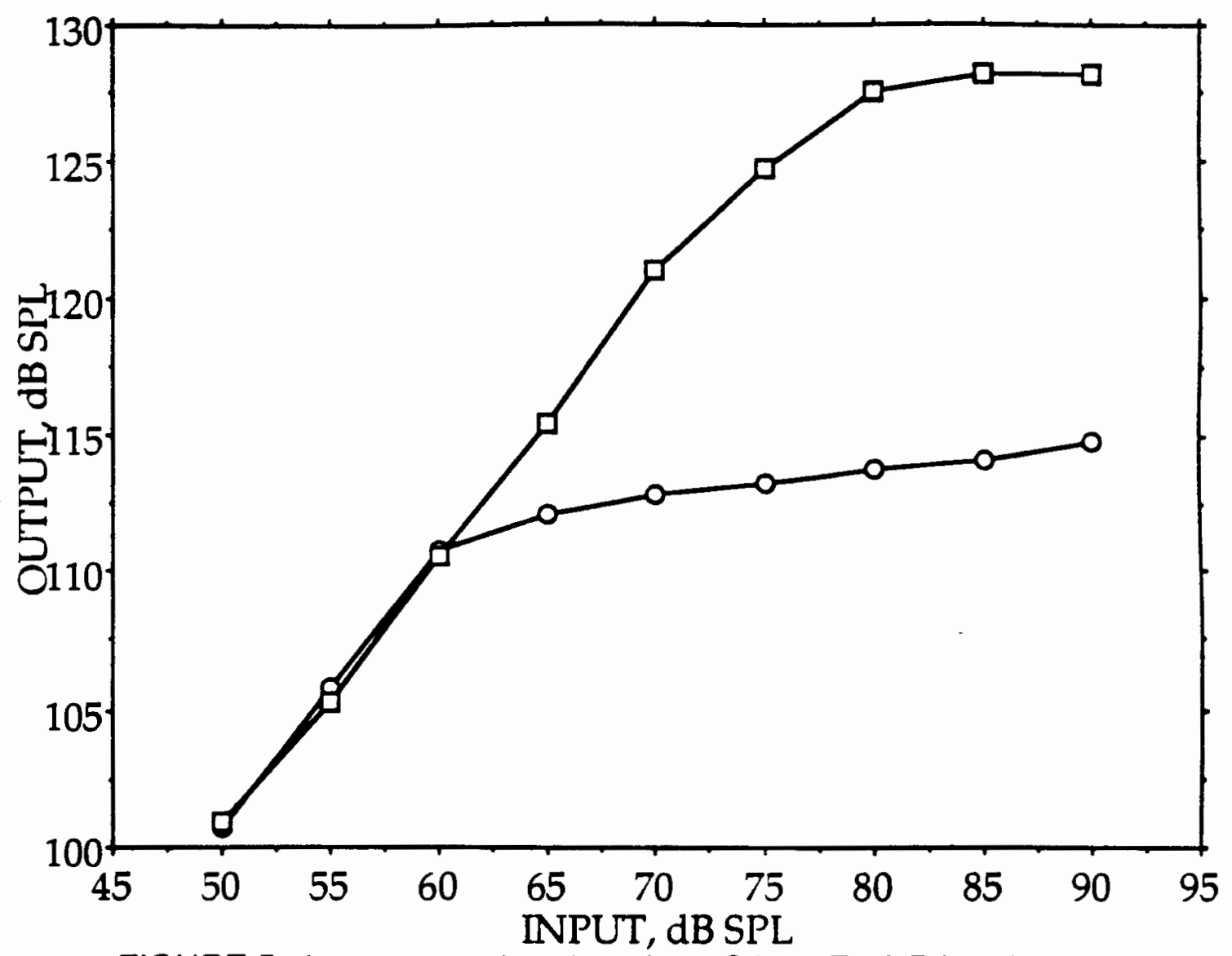

FIGURE 5. Input-output functions for a Oticon E $38 \mathrm{P}$ hearing aid. Output of hearing aid in $\mathrm{CB}$ SPL, is plotted as a function of level of a $3000 \mathrm{~Hz}$, continuous tone input. Curves are shown for AGC set to the full-on position (circles) and AGC set to mimimum position (squares). 
Figures 6 and 7 are input-output curves for the Unitron UE 10 with 1 cycle of a $3000 \mathrm{~Hz}$ tone as input. Again, input-output curves are shown for the hearing aid set to minimum and maximum compression. Figures 6 illustrates that in the Unitron UE 10, a slight difference did exist in output between the AGC minimum condition and the AGC full-on condition. Specifically, the input-output curves for the $A G C$ full-on is up to $3 \mathrm{~dB}$ lower than for the $\mathrm{AGC}$ minimum condition. However, this difference between the output is small, and the reduction in output does not approximate the output reduction for a continuous $3000 \mathrm{~Hz}$ tone with AGC full-on. Figure 7 shows the output of the Unitron UE 10 hearing aid with the transient signal input and the AGC full on, compared to the output with a continuous $3000 \mathrm{~Hz}$ tone input and the compression full on. The output of the hearing aid with the transient is not reduced, meaning that the compression is not being activated by the transient. In fact, if we compare the output of the Unitron with the transient input and AGC full on to the continuous tone with AGC off (Figure 8) they are very similar. These results indicate that in the Unitron UE 10 the transient signal does not fully activate the compression system when presented alone with the AGC full on.

Figure 9 shows the input-output curves for the Oticon E $38 \mathrm{P}$, which is an output compression hearing aid. It reacted somewhat differently than the Unitron UE 10 to the transient signal. The AGC off condition with a transient input is very similar to that of the Unitron UE 10 (Figure 6), in that no reduction in the output of the hearing aid is taking place except for input levels greater than $80 \mathrm{~dB}$. That is, the hearing aid acts like a linear, or non-AGC hearing aid. However, the Oticon $E 38 \mathrm{P}$ reacted very differently when the compression was full on. The output of the transient signal is reduced by up to $10 \mathrm{~dB}$ and comes within $5 \mathrm{~dB}$ of that of the continuous tone with AGC full on for input levels of 75$90 \mathrm{~dB}$. This indicates that the compression system is activated to some degree 


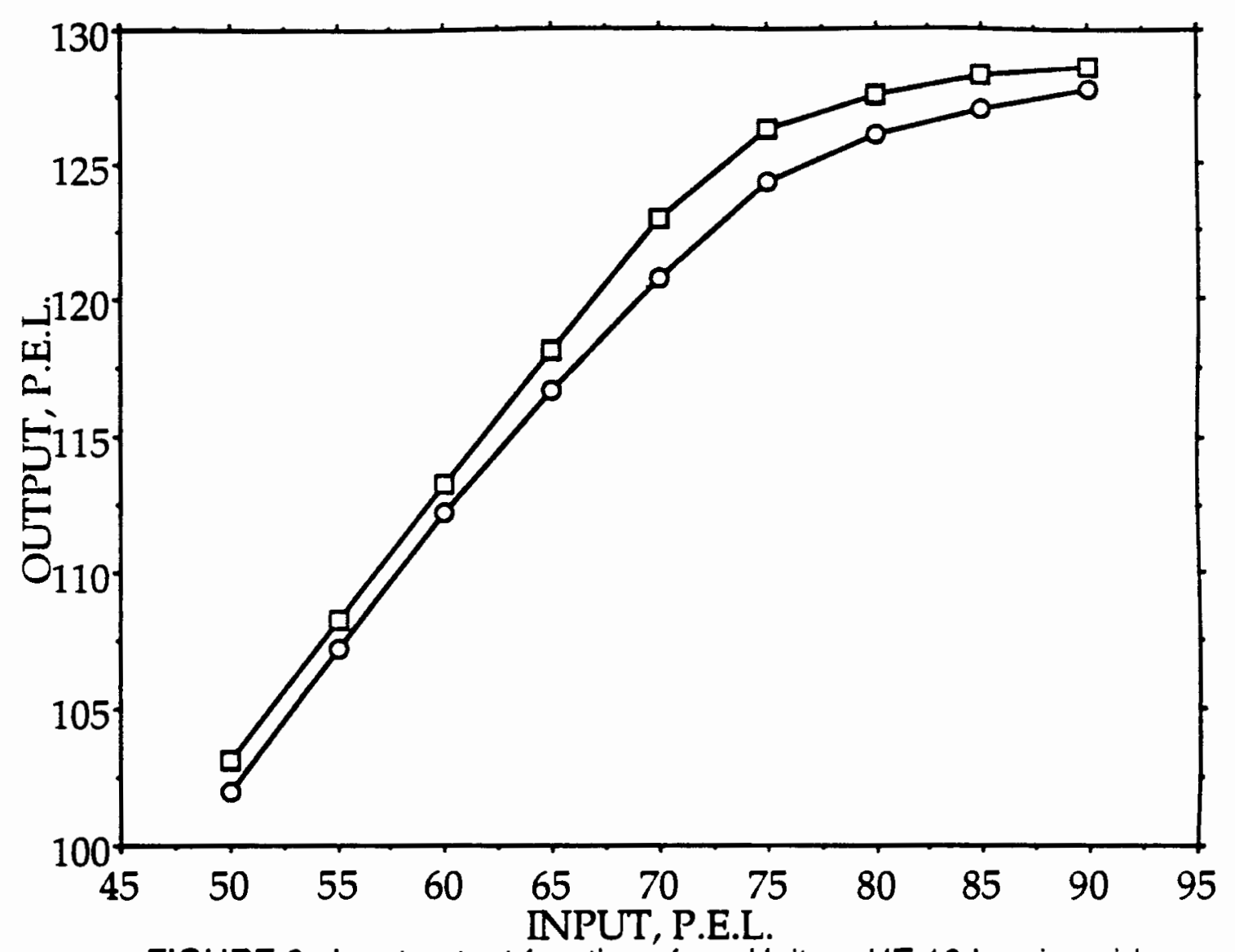

EIGURE 6. Input-output functions for a Unitron UE 10 hearing aid in response to a transient signal with AGC set to the full-on position (circles) and AGC set to minimum position (squares). Input and output levels are plotted in $\mathrm{dB}$ peak equivalent level (P.E.L.). 


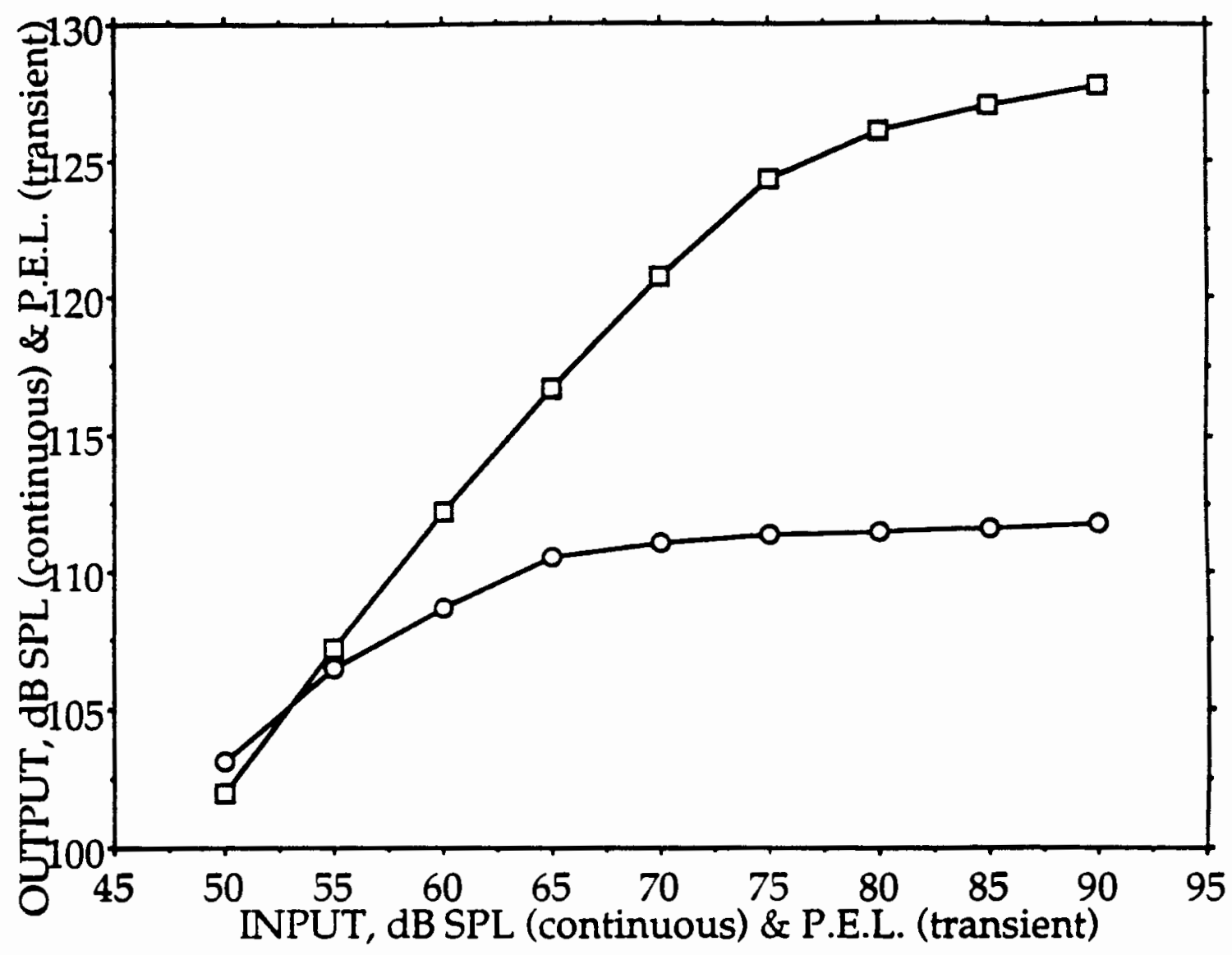

FIGURE 7. Input-output functions for a Unitron UE 10 hearing aid in response to a continuous $3000 \mathrm{~Hz}$ tone (circles) and for a transient signal (squares). Input and output levels are plotted in $\mathrm{dB}$ SPL for the continuous $3000 \mathrm{~Hz}$ tone and are plotted in $\mathrm{dB}$ peak equivalent level (P.E.L.) for the transient signal. 


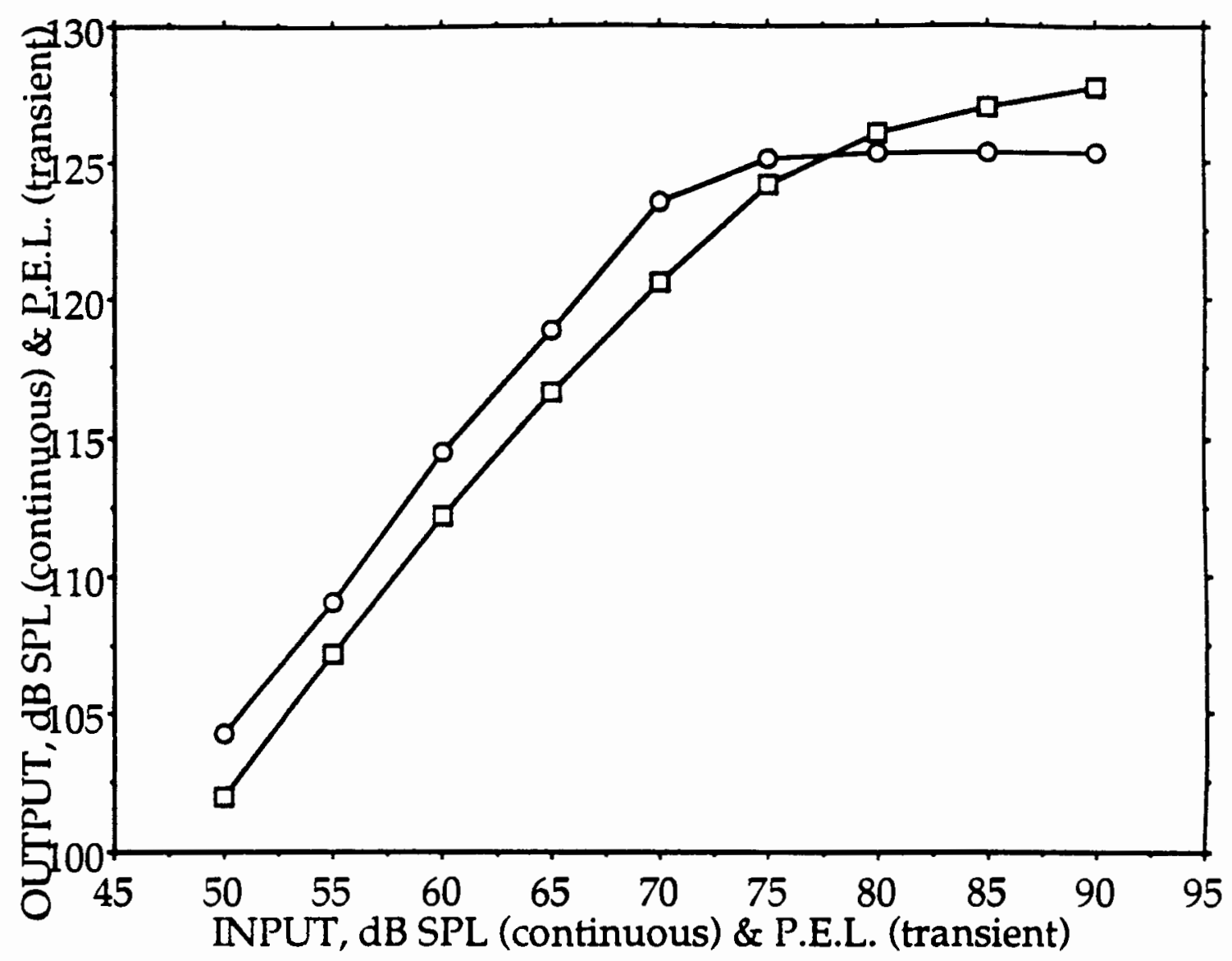

EIGURE 8. Input-output functions for a Unitron UE 10 hearing aid in response to a continuous $3000 \mathrm{~Hz}$ tone with AGC set at minimum (circles) and the output of the aid to a transient signal with AGC full-on (squares). Input and output levels are plotted in $\mathrm{dB}$ SPL for the continuous $3000 \mathrm{~Hz}$ tone and are plotted in $\mathrm{dB}$ P.E.L. for the transient signal. 


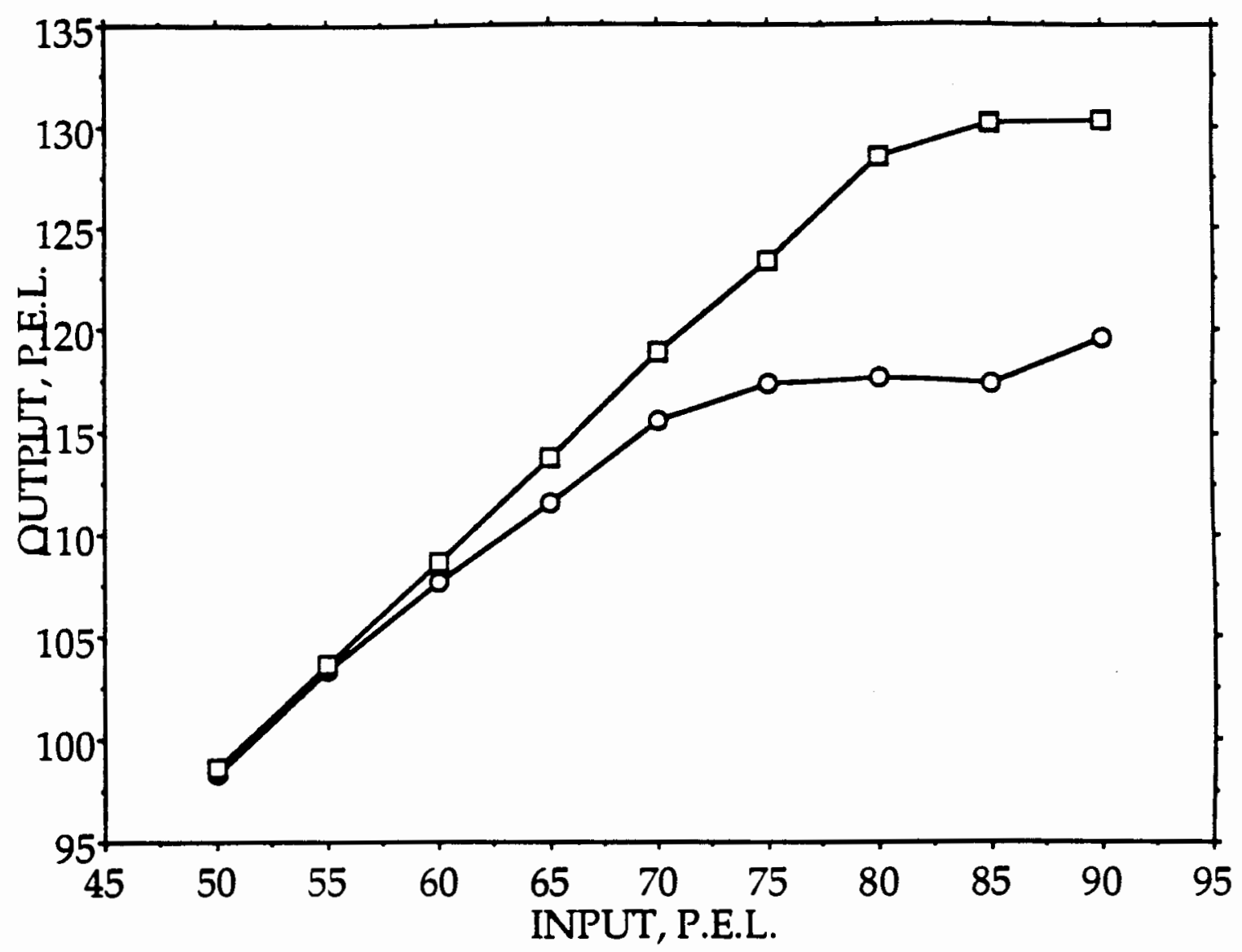

FIGURE 9. Input-output function for a Oticon E $38 \mathrm{P}$ hearing aid in response to a transient signal with AGC set to full-on position (circles) and AGC set to minimum position (squares). Input and output levels are plotted in P.E.L. 
by the transient alone in the Oticon. Figure 10 shows the input-output function of the Oticon E 38 P hearing aid with the transient signal and the AGC full on, compared to the output of a continuous $3000 \mathrm{~Hz}$ tone with the AGC full on. These results indicate that the compression system is being activated by the transient signal in some fashion because the transient signal output is somewhat similar (within $5 \mathrm{~dB}$ ) to that of the continuous $3000 \mathrm{~Hz}$ tone with AGC full on.

The results for the Bernafon T86, Siemens 234 PP AGC I and the Audiotone A52S were similar to those of the Unitron UE 10 under these same conditions. Thus, the compression circuit of all but one of the the hearing aids examined in this study did not appear to be activated by the transient signal alone. When it does activate the AGC as in the case of the Oticon E $38 \mathrm{P}$, it does not activate it to the same degree as for a continuous tone.

Figure 11 shows the time waveforms of the output of a Unitron UE 10 hearing aid. The waveform on the left is the output of the hearing aid with the transient signal being presented alone, while the waveform on the right is the output of the aid when the transient signal is presented in conjunction with a 10 $\mathrm{KHz}$ (activator) tone. It is clear that when the transient is presented with a high frequency tone, its output amplitude is reduced. Notice, however, that the high frequency tone is not evident in the output of the hearing aid. Thus, the compression system of the hearing aid is being activated by the high frequency tone even though the tone does not show up in the output of the hearing aid.

In order to determine the optimal frequency to use in activating the compression circuit, the amplitude of the transient signal at the output of each hearing aid was measured as a function of frequency of the activator. Figure 12 shows an example of this for the Unitron UE 10 with compression full-on. Specifically, the amplitude of the transient signal output is plotted as a function 


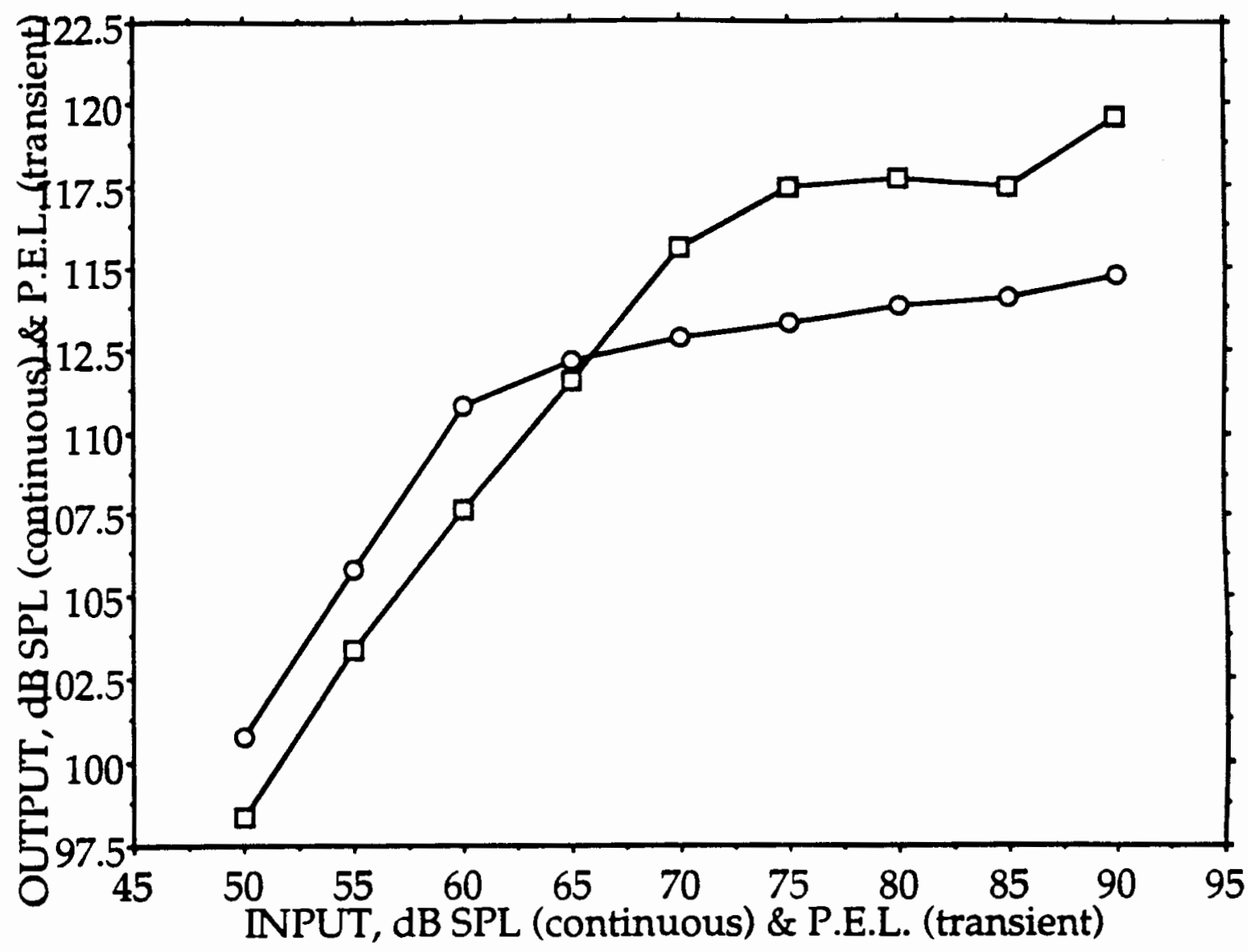

FIGURE 10. Input-output functions for an Oticon E 38 P hearing aid with AGC set to full-on, for a continuous $3000 \mathrm{~Hz}$ tone (circles) and for a transient signal (squares). Input and output levels are plotted in dB SPL for the continuous tone and P.E.L. for the transient signal. 

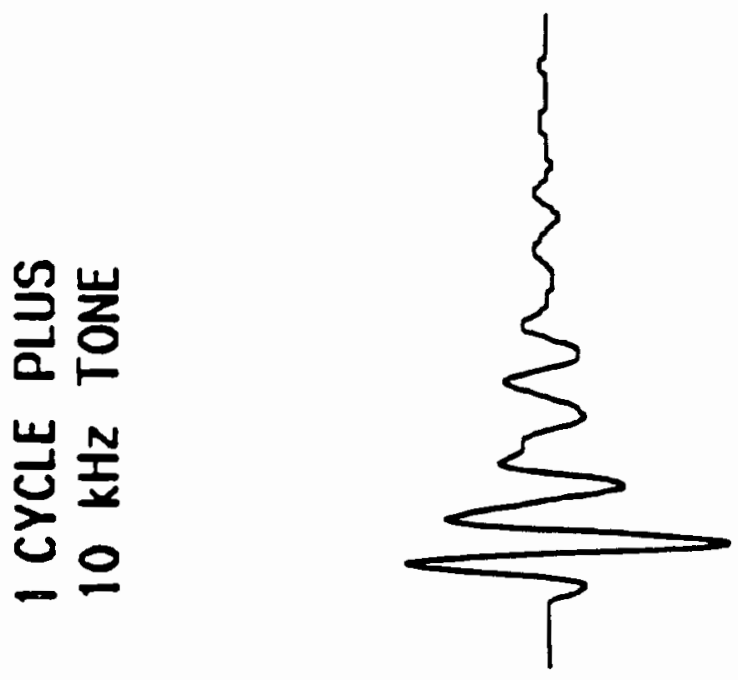

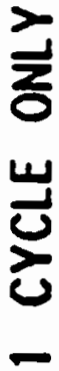

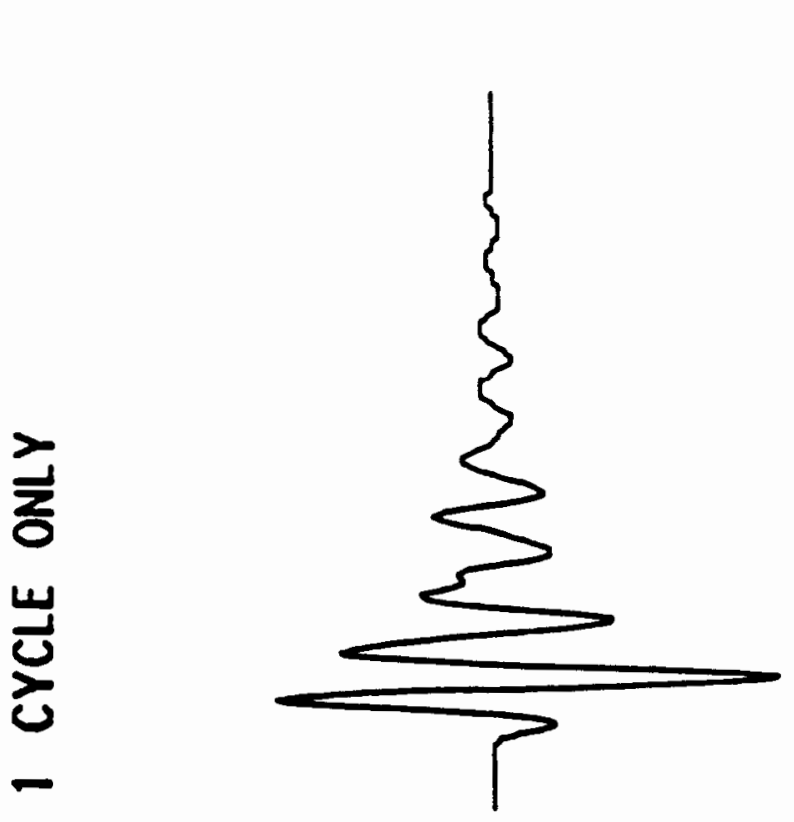

崖

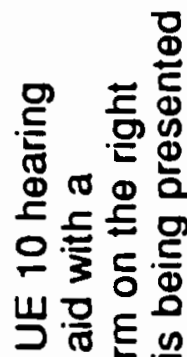

동잉응

틀 원옹

5 这

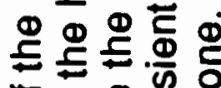

눙호은

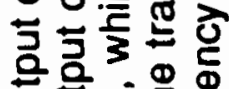

궁윽

옹원

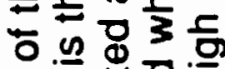

n들을

토용ㅇㅇㅇ

으용용

$\$$ 든듀잉

元 50 잉

ไ은오

통 요욜

트윰ㄷㄴ

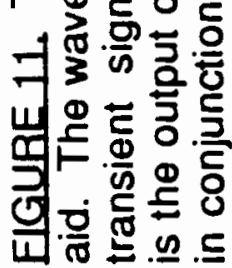

JOnLI TdW $\forall$ 


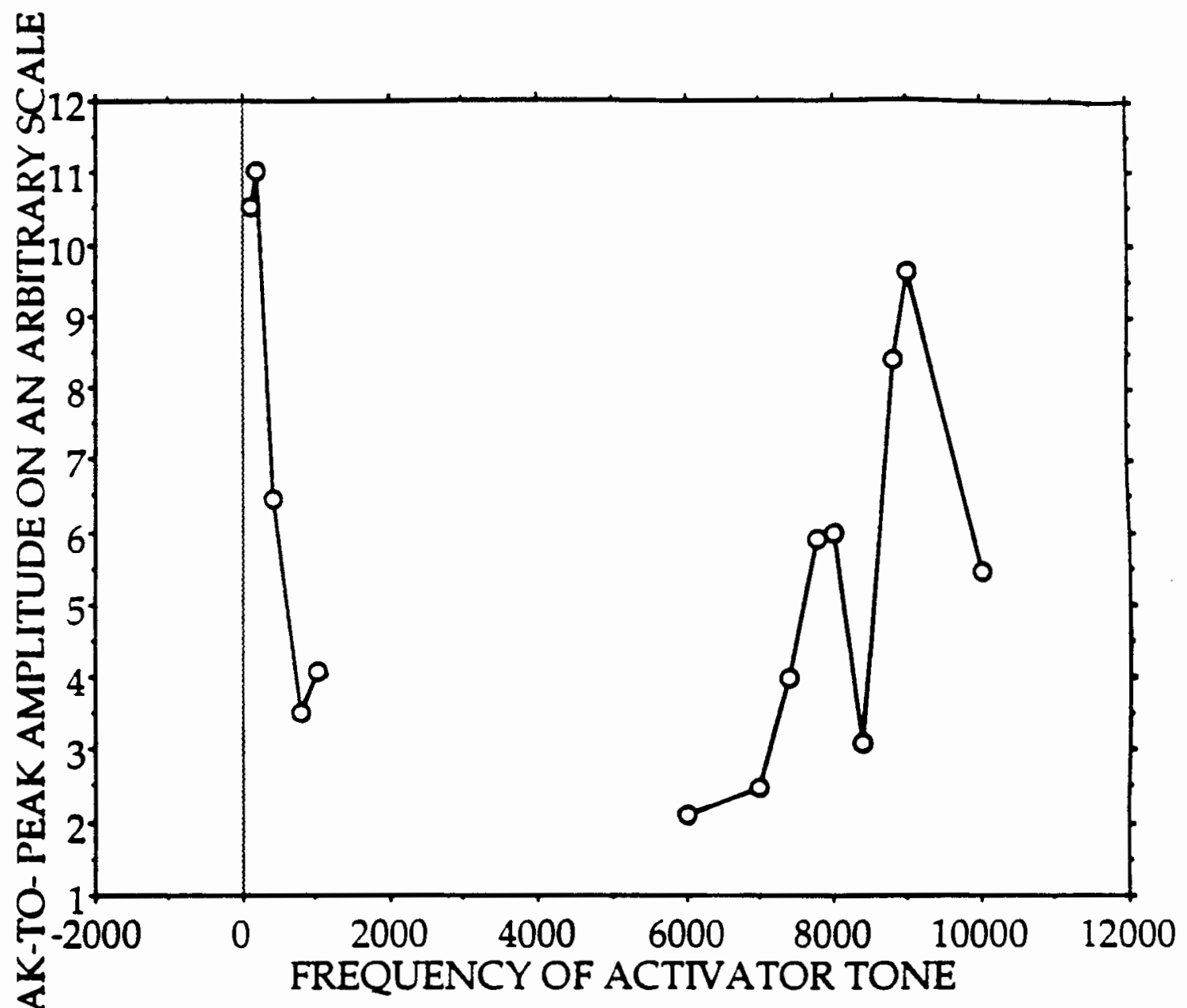

EIGURE12. Amplitude of a transient signal at the output of a Unitron UE 10 hearing aid as a function of activator frequency. 
of activator frequency. The activator was presented at $80 \mathrm{~dB}$ SPL. The amplitude is smallest in the $6-7 \mathrm{KHz}$ region, indicating that the output of the transient signal is reduced to the greatest degree by activators in this frequency range. However, it should be noted that although the transient level was in fact reduced, the activator was present in the output of the hearing aid at these frequencies. For this reason, these frequencies could not be used to reduce the output. An activator frequency of $7400 \mathrm{~Hz}$ was chosen for the Unitron because it was able reduce the amplitude of the transient without being present in the output of the hearing aid. For other hearing aids the optimal frequency of the activator tone ranged in frequency from $7-8 \mathrm{KHz}$, and depended on the frequency response characteristics of the given hearing aid. Note, also in figure 12 that their are no data points for the frequencies between .8 and $4 \mathrm{KHz}$. This was due to the fact that most hearing aids are able to easily pass frequencies from about $.5-5 \mathrm{KHz}$. As a result, the activator tone was present in the output of the aid to such an extent that it was impossible to get an amplitude reading of the transient over this range of frequencies. This was true for all hearing aids tested.

The effects of the high frequency activating tones on the input-output functions for the transient signals are illustrated for all five hearing aids in figures 13-17. Input-output functions are plotted for the following conditions for each aid: 1) continuous $3000 \mathrm{~Hz}$ tone input, AGC full on (circles), 2) transient signal alone with AGC full on (squares), 3) transient plus the high frequency tone activator at a constant level (diamonds) and 4) transient plus high frequency tone at variable level (triangles). Figure 13 represents data obtained from the Unitron UE 10. The data points represented by circles show the output of a continuous $3 \mathrm{KHz}$ tone with AGC full on, while the squares represent the transient signal alone. These curves were shown previously in different 


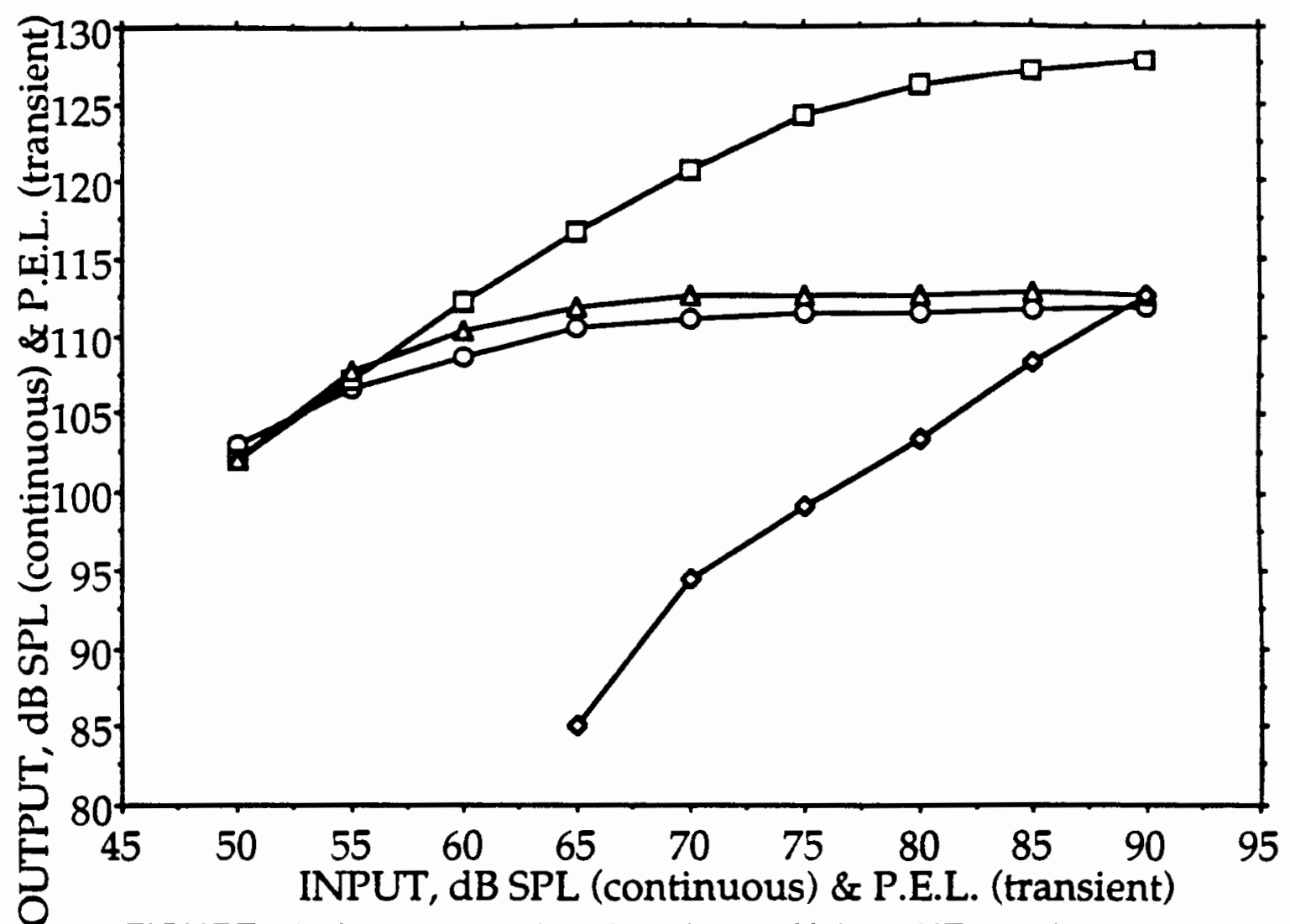

FIGURE 13. Input-output functions for the Unitron UE 10, showing the effect of a high frequency activator tone on the output of the hearing aid for a transient signal with AGC full-on. Curves for the transient signal alone with with $A G C$ full-on (squares) and the continuous $3 \mathrm{KHz}$ tone with AGC full-on (circles) are compared to the output of the hearing aid in response to a transient signal with a $7.4 \mathrm{KHz}$ activator tone at a variable level (triangles) and a transient with activator at one continuous level (diamonds). 
combinations in figures $4,6,8$ and 9 . The diamonds represent the transient output with a $7.4 \mathrm{KHz}$ tone at a constant level of $96.3 \mathrm{~dB}$ SPL. This level was obtained by adjusting the level of the activator until it reduced the amplitude of the transient signal to a value equal to the amplitude of the continuous $3 \mathrm{KHz}$ tone with AGC full-on at the output of the hearing aid with a $90 \mathrm{~dB}$ input. The triangles represent the level of the transient plus a $7.4 \mathrm{KHz}$ tone activator at a variable level. That is, the $7.4 \mathrm{KHz}$ tone is increased in $5 \mathrm{~dB}$ steps as the transient signal is increased in $5 \mathrm{~dB}$ steps. This figure shows that the activator tone at a variable level is able to reduce the output of the hearing aid to levels similar to those of a continuous $3 \mathrm{KHz}$ tone with AGC on. However, with a continuous level activator, the output is reduced to a level below that of a continuous tone alone. This is apparently due to the compression causing a fixed gain reduction of about $30 \mathrm{~dB}$ regardless of input levels.

Data for the Oticon seen in figure 14 is unique in that the transient is activating the compression by itself. When the activator tone is added at a variable level, the output of the hearing aid for the transient signal is reduced to an even lower level than for the continuous tone, AGC full-on condition. This indicates that both the transient signal and the continuous high frequency are activating the compression. As with the Unitron, the activator presented at a constant level reduced the output to a greater degree than needed.

Figures 15, 16 and 17 show this data for the Bernafon T86, the Siemens 234 PP AGC I, and the Audiotone A-52S respectively. Data for the Bernafon T 86 (Figure 15) indicates that the constant-level $7400 \mathrm{~Hz}$ tone does activate the compression. However, when the level of the activator tone is varied with the transient input, it does not seem to activate the compression to the degree desirable. That is, the output still remains about $10 \mathrm{~dB}$ higher than for the continuous $3 \mathrm{KHz}$ tone with AGC on. This again could also be caused by 


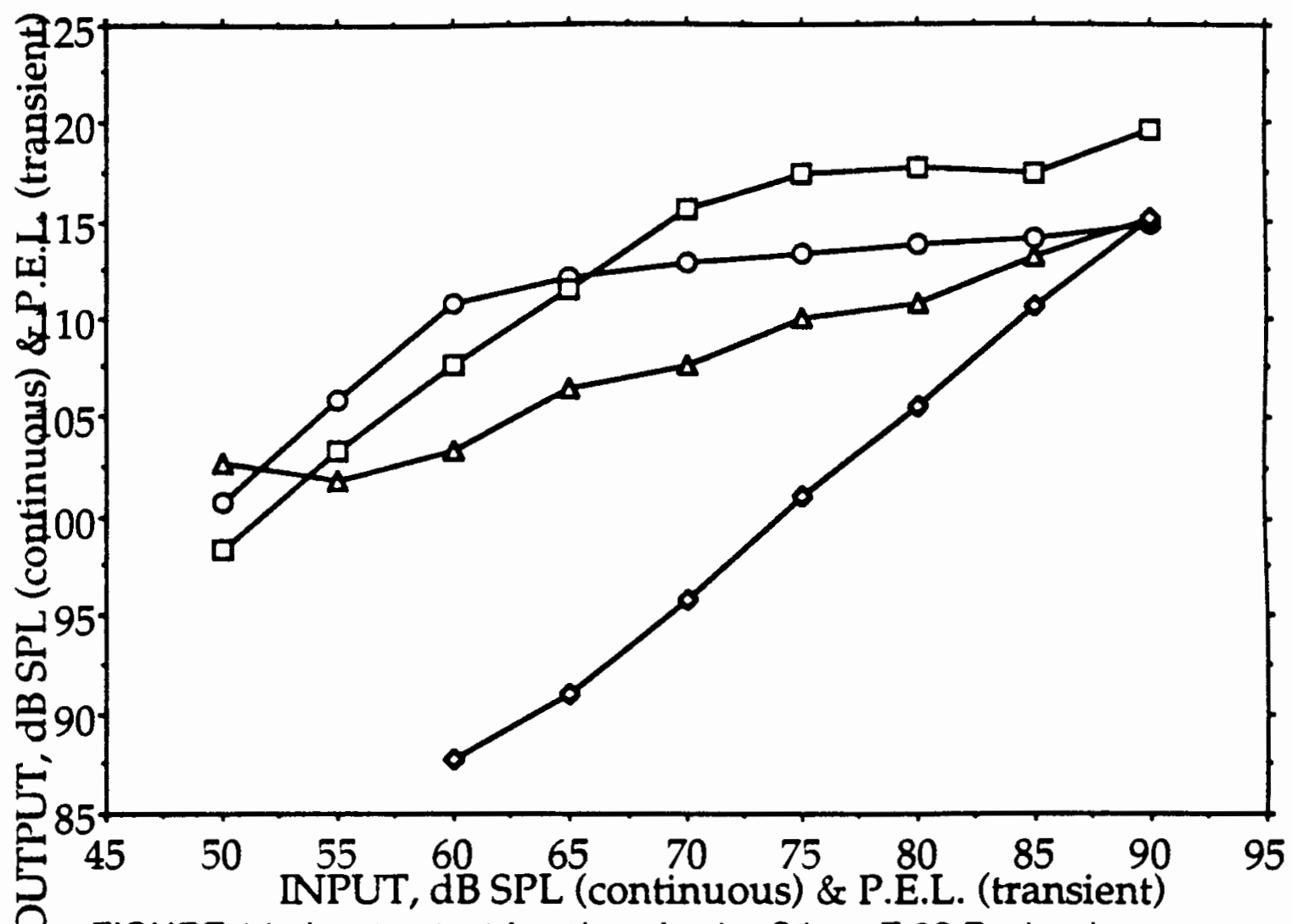

EIGURE 14. Input-output functions for the Oticon E $38 \mathrm{P}$, showing the effect of a high frequency activator tone on the output of the hearing aid for a transient signal with AGC full-on. Curves for the transient signal alone with the AGC full-on (squares) and the continuous $3 \mathrm{KHz}$ tone with AGC full-on (circles) are compared to the output of the hearing aid in response to a transient signal with a 7.4 $\mathrm{KHz}$ activator tone at a variable level (triangles) and a transient with activator at one continuous level (diamonds). 


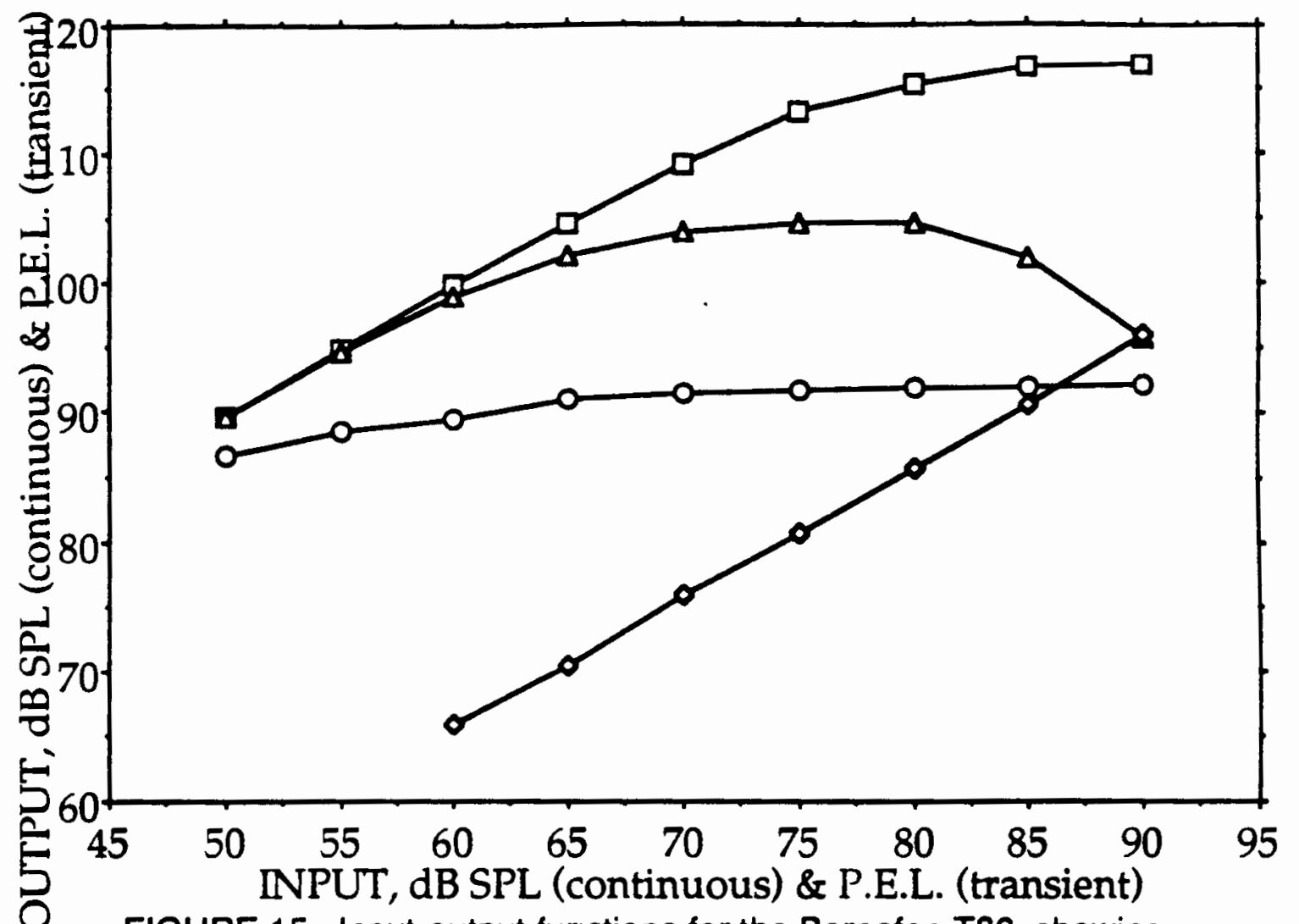

FIGURE 15. Input-output furctions for the Bernafon T86, showing the effect of a high frequency activator tone on the output of the hearing aid for a transient signal with AGC full-on. Curves for the transient signal alone with the AGC full-on (squares) and the continuous $3 \mathrm{KHz}$ tone with AGC full-on (circles) are compared to the output of the hearing aid in response to a transient signal with a $7.4 \mathrm{KHz}$ activator tone at a variable level (triangles) and a transient with activator at one continuous level (diamonds). 


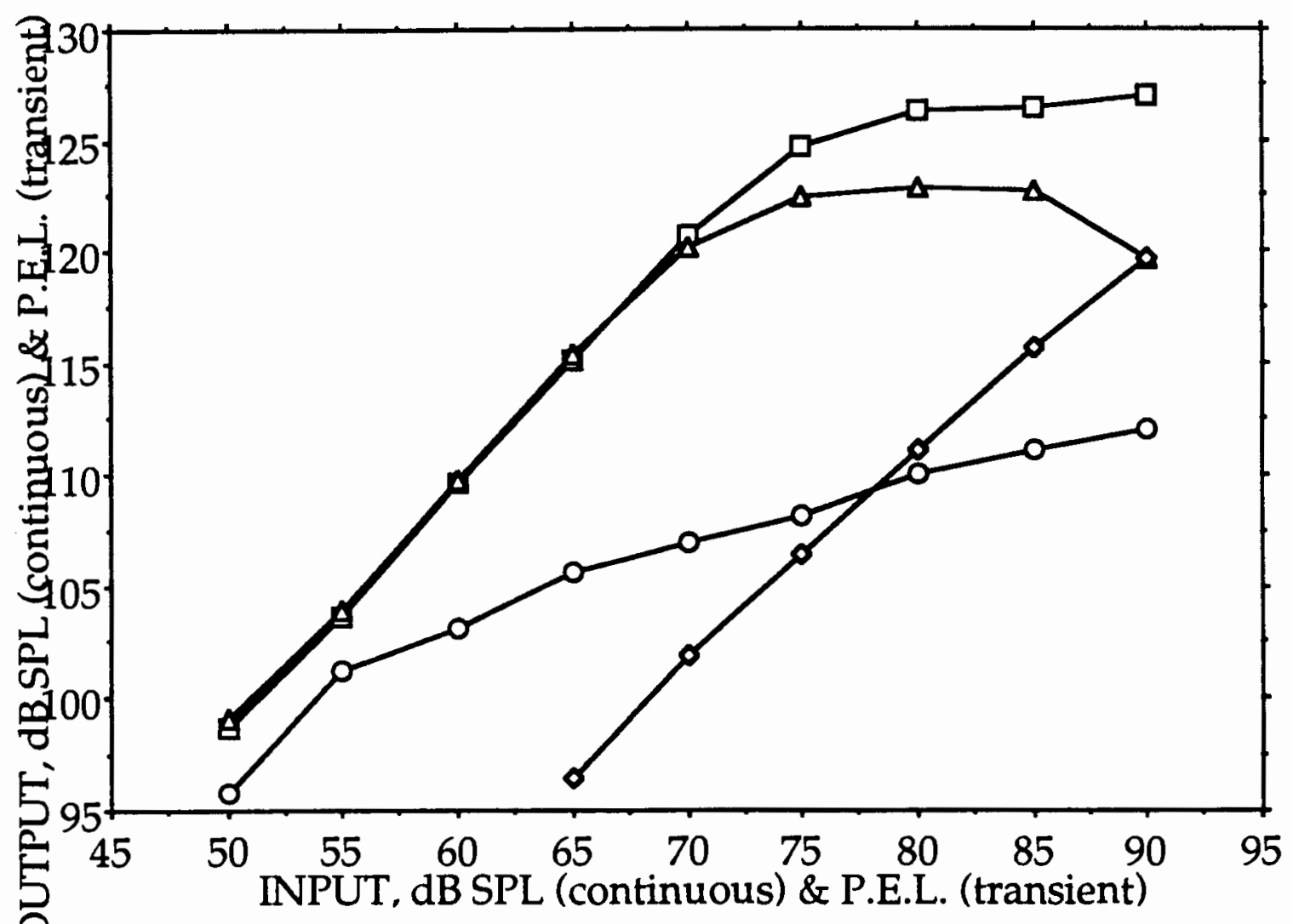

EIGURE 16. Input-output functions for the Siemens PP AGC I, showing the effect of a high frequency activator tone on the output of the hearing aid for a transient signal with AGC full-on. Curves for the transient signal alone with the AGC full-on (squares) and the continuous $3 \mathrm{KHz}$ tone with AGC full-on (circles) are compared to the output of the hearing aid in response to a transient signal with a $7.4 \mathrm{KHz}$ activator tone at a variable level (triangles) and a transient with activator at one continuous level (diamonds). 


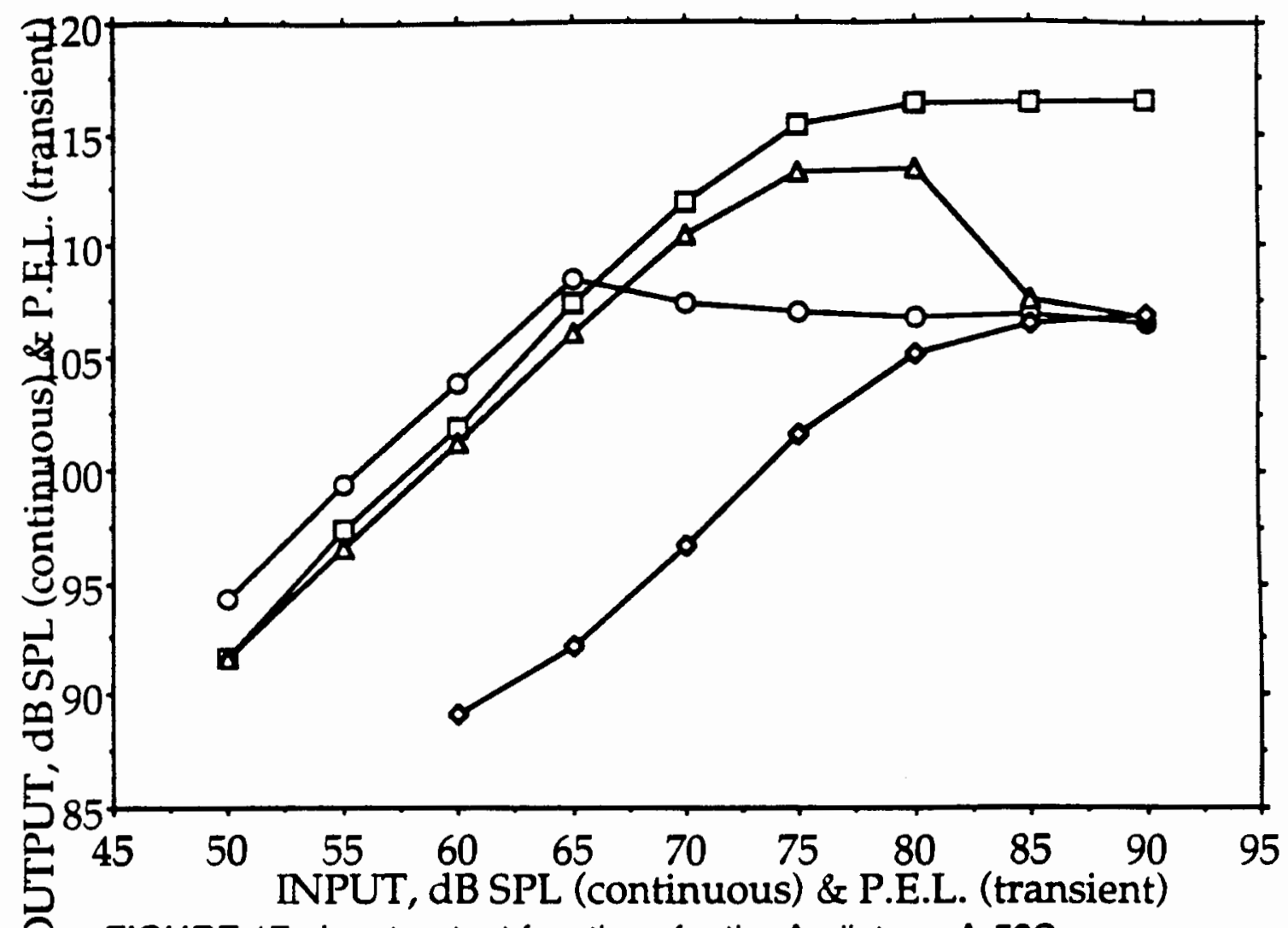

EIGURE 17. Input-output functions for the Audiotone A-52S, showing the effect of a high frequency activator tone on the output of the hearing aid for a transient signal with AGC full-on. Curves for the transient signal alone with the AGC full-on (squares) and the continuous $3 \mathrm{KHz}$ tone with AGC full-on (circles) are compared to the output of the hearing aid in response to a transient signal with a 7.4 $\mathrm{KHz}$ activator tone at a variable level (triangles) and a transient with activator at one continuous level (diamonds). 
compression causing a fixed gain reduction regardless of input level. When the $7400 \mathrm{~Hz}$ tone is held at one level it produces a constant reduction in output of the transient, resulting in too low an output. That is, the input-output function for this condition falls below that of the continuous $3 \mathrm{KHz}$ tone with AGC full-on. It should also be noted that the compression system is not activated by the transient signal alone. This is evident by the the fact that the input-output function for the transient signal alone with AGC full on is higher than that of the continuous tone with AGC full on.

Data for the Siemens PP AGC I presented in figure 16 is very similar to that of the Bernafon in that. With a continuous $7800 \mathrm{~Hz}$ activator tone at a constant level, the compression was activated and the output was reduced to a much greater degree than needed. Data for the Siemens with a variable level activator is similar to that of the Bernafon (Figure 15) except for the fact that the output of the transient signal could not be reduced to the level of the continuous AGC on condition. This was because of equipment limitations, it was not possible to get the level of the activator high enough to reduce the output of the transient signal.

Figure 17 shows the data for the Audiotone A-52S. This figure indicates that the transient signal does not activate the compression system. However, the compression circuit is activated by the $7400 \mathrm{~Hz}$ activator tone and is in fairly good agreement (within $5 \mathrm{~dB}$ ) with the continuous $3 \mathrm{KHz}$ tone with $\mathrm{AGC}$ on at the high transient signal input levels $(75-90)$. It should also be noted that the plot for the continuous tone AGC on condition is not what is expected for this condition. That is, the curve for the $3 \mathrm{KHz}$ continuous tone with AGC full-on actually has a 2-3 dB higher output at $60 \mathrm{~dB}$ input as compared to those at 65$90 \mathrm{~dB}$ input. We would expect the output to remain constant or slightly increase as input is increased, as does the output for the transient with activator at one 
level. It is possible that the compression system was not functioning correctly during this experiment, however all hearing aid were tested for proper functioning prior to data collection.

Figure 18 illustrates the effect of high pass noise on the input-output functions of the transient for the Unitron UE 10, while figure 19 represents data obtained for the Oticon E $38 \mathrm{P}$ for the same conditions. Data obtained for the Unitron UE 10 with a high pass noise as an activator are very similar to data obtained with a high frequency tone as activator. Again, the activator at a variable level is capable of reducing the amplitude of the transient signal at the output of the hearing aid, making it is similar to that of a continuous tone with AGC full on. It also shows that the high pass noise at a continuous level does not achieve the desired input-output curve.

Figure 19 indicates that the output of the Oticon E 38 P with a transient signal and a high pass noise activator as input is very similar to that of the output with a high frequency tone as the activator. Data for the other three hearing aids using a high pass noise as activator indicated that the high pass noise outputs were either similar to that of a tonal activator, or did not activate the compression as well as the high frequency tone. One exception was noted in the Audiotone A 52S, (Figure 20) where the high pass noise actually activated the compression to a greater degree than the high frequency tone or even the continuous $3000 \mathrm{~Hz}$ tone alone with AGC full on.

An attempt was also made to use use a low pass noise as an activator with a high frequency cutoff of $500 \mathrm{~Hz}$ or lower. This was unsuccessful because the noise was present in the output of hearing aid and the transient signal was not discernible. 


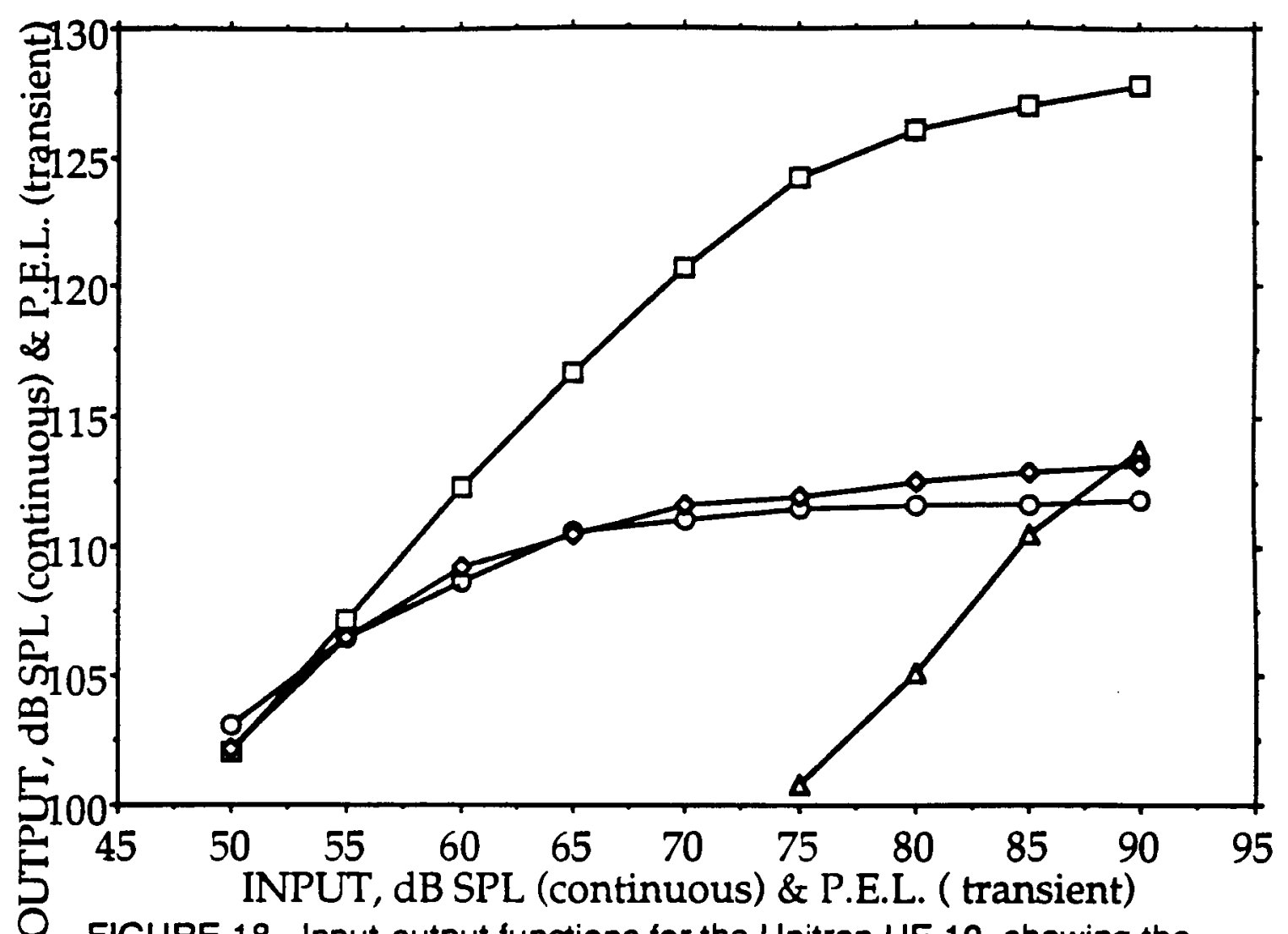

EIGURE 18. Input-output functions for the Unitron UE 10, showing the effect of a high pass noise on the output of the hearing aid for a transient signal with AGC full-on. Curves for the transient signal alone with the AGC full-on (squares) and the continuous $3 \mathrm{KHz}$ tone with AGC full-on (circles) are compared to the output of the hearing aid in response to a transient signal with a high pass noise activator at a variable level (triangles) and a transient with activator at one continuous level (diamonds). 


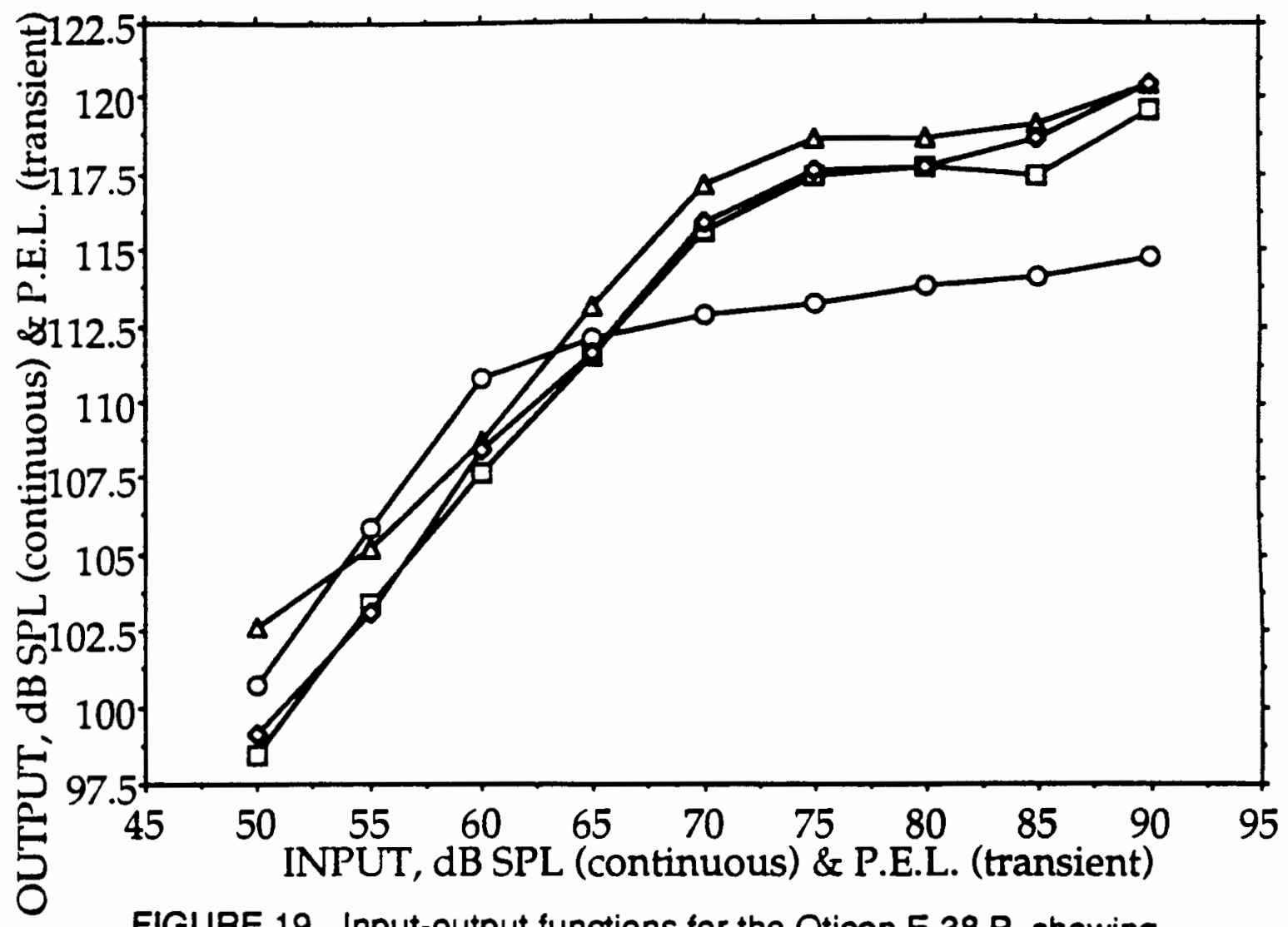

FIGURE 19. Input-output functions for the Oticon E $38 \mathrm{P}$, showing the effect of a high pass noise on the output of the hearing aid for a transient signal with AGC full-on. Curves fir the transient signal alone with the AGC full-on (squares) and the continuous $3 \mathrm{KHz}$ tone with AGC full-on (circles) are compared to the output of the hearing aid in response to a transient signal with a high pass noise activator at a variable level (diamonds) and a transient with activator at one continuous level (triangle). 


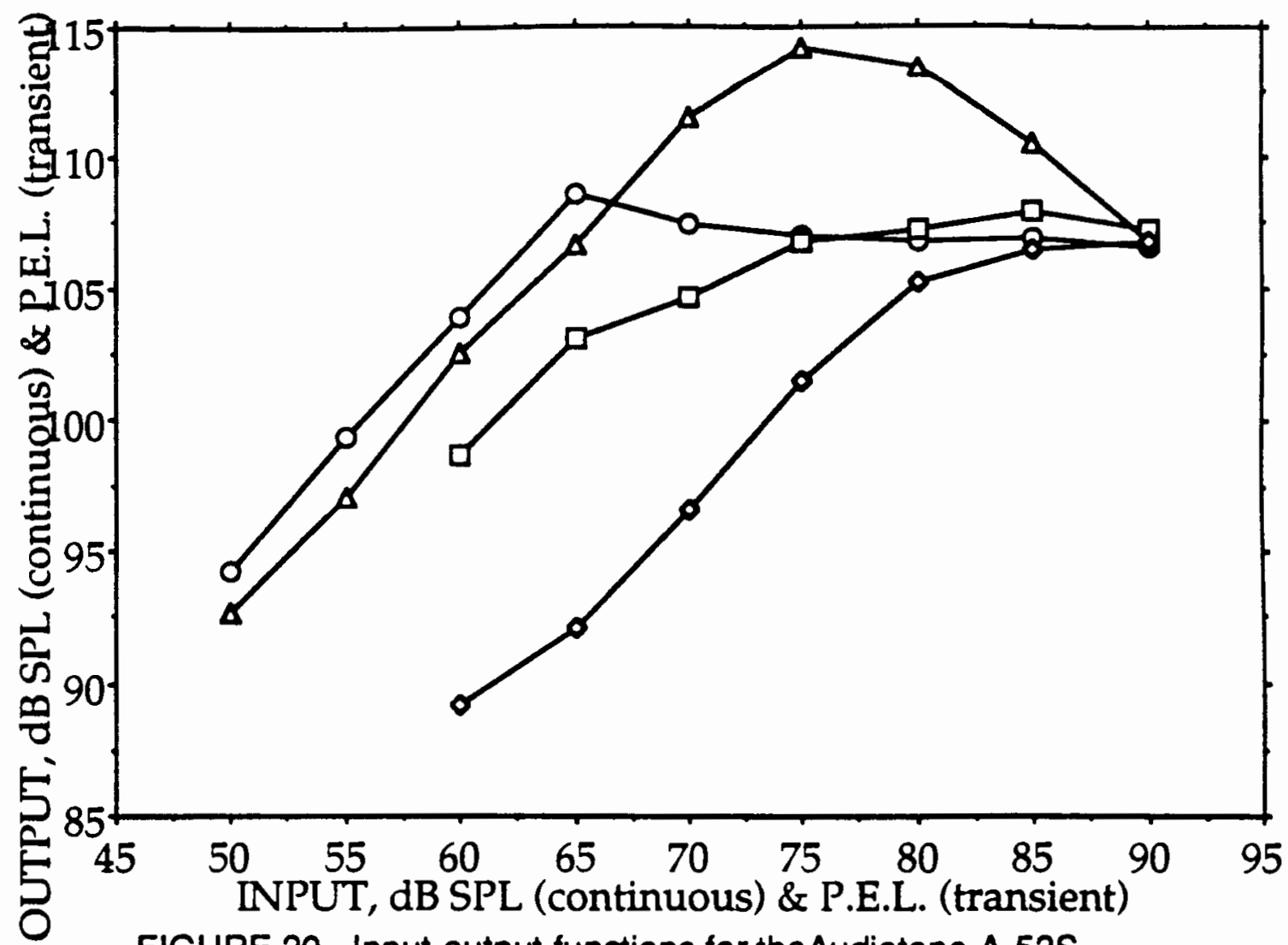

FIGURE 20. Input-output functions for theAudiotone A-52S, showing the effect of a variable level high pass noise (triangles) as well as a high pass noise at 1 level (squares) has on the output of the hearing aid with a transient signal input. These are compared to the high frequency tonal activator at 1 level (diamonds). The transient with noise at one level (squares) is in better agreement with the continuous $3 \mathrm{KHz}$ tone with AGC full-on (circles) than any other condition. 


\section{CHAPTER V}

\section{DISCUSSION}

The purpose of this study was to determine if the input-output function (i.e. output levels of the hearing aid as a function of input level) for'a transient signal could be made to approximate that of a continuous signal by activating the compression circuit with a second signal. The level and frequency of the AGC activating tone was varied. The input-output function of the hearing aid was then examined to determine if: 1 . the AGC was activated and the transient signal output approximates that of a continuous tone, and 2 . if the second tone is visible in the output of the hearing aid, and thus, potentially being an interfering factor in $A B R$ measurement.

It was revealed that in four out of five hearing aids studied, the compression circuit is not activated by a transient signal alone, which is in agreement with many authors including, Gorga, Beauchaine \& Reiland (1987), Beauchaine and Gorga (1988), Kiessling (1982) and Stecker (1982). However, in the Oticon E $38 \mathrm{P}$, which has the shortest attack time of all the hearing aids tested, at $4 \mathrm{~ms}$, compared to the other aids which have attack times in the $10 \mathrm{~ms}$ area, the transient signal did activate the compression circuit, reducing output by up to $10 \mathrm{~dB}$. The output was within $5 \mathrm{~dB}$ of the output for a continuous, $3 \mathrm{KHz}$ tone input with AGC full-on. This agrees with the findings of Hecox (1983) and Mahoney (1985) that the compression circuit is indeed activated by transient signals used in ABR testing. Thus, it may be concluded that different hearing 
aids process transient signals differently and this may be related to the attack and release times of the hearing aid, however, no studies have been done to confirm this. The fact that in some hearing aids the compression is not activated by a transient signal has important implications for measuring ABR's in aided ears. Specifically, the output level of the hearing aid may be higher than desired when doing aided ABR's. This is possible in that, if the compression circuit of a hearing aid is not activated, no reduction in output is occuring for a given signal, however, if a signal is able to activate the compression, a reduction in the output will occur at a given input or output level. Thus, It also brings into question question some of the research that has been done by others including Hecox (1983) and Mahoney (1985), who may have actually had higher outputs for transient signals than they believed. Therefor, the true characteristics of the hearing aid may not have been evaluated when doing aided ABR's at levels that would activate the compression in normal listening conditions. That is, they may have thought the compression was activated when in fact it wasn't.

The results of this study indicate that the use of an activator tone of either a high frequency tone or high pass noise is effective in reducing the output of a transient signal in most hearing aids. However, it was not capable of reducing the output of the transient signal to a value close to that of a continuous tone with AGC full-on. Specifically, results indicated that for most hearing aids, the activator at one constant level reduced the output of the transient signal too much. Also, the compression was typically not activated enough when the activator level was varied with the transient signal.

One exception was found with the Unitron UE 10, where it was possible to reduce the output of the transient signal to a level within $3 \mathrm{~dB}$ of that of a continues tone with AGC full-on with a high frequency tone as well as with a 
high pass noise at variable levels. That is, the output for the Unitron UE 10 with a transient signal could be made to approximate that of a continuous tone.

Thus, the original goal of activating the compression circuit with some type of high frequency activator tone or noise was only accomplished in one of the five hearing aids, and it was only possible when the activator signal was varied with the transient input.

In conclusion, different hearing aids act somewhat differently to transient signals. Also, although an extra high frequency tone or noise can activate the compression circuit of most hearing aids, it generally does not reduce the output of the hearing aid to the desired level. Only for one hearing aid was this possible, and it required a great amount of time and instrumentation. This method therefor does not seem very promising in the clinical measurement of aided ABR's. That is, the instrumentation and procedure does not allow for a clinically viable method. In fact, it would probably be much simpler to obtain the desires output by simply using a variable level input. 


\section{REFERENCES}

American National Standards Institute/ Acoustical Society of America. (1982). American National Standards Specification of Hearing Aid Characteristics, ANSI S3.22-1982. New York: ANSI.

Beauchaine, K. A., \& Gorga, M. P. (1988). Applications of the auditory brainstem response to pediatric hearing aid selection. Seminars in Hearing, 9 (1), 61-74.

Beauchaine, K. A., Gorga, M. P., Reiland, J. K., \& Larson, L.L. (1986). Applications of ABR's to the hearing aid selection process: Preliminary data. Journal of Speech and Hearing Research, 29, 120-128.

Coats, A. C., \& Martin, J. L. (1977). Human auditory nerve action potentials and brain stem evoked responses: Effects of audiogram shape and lesion location. Archives of Otolaryngology. 103, 605-622.

Cox, C., \& Metz, D. (1980) ABER in the prescription of hearing aids. Hearing Instruments. 31 (9) 12-15, 55.

Don, M., Eggermont, J.J., \& Brackman, D.E. (1979). Reconstruction of the audiogram using brainstem response and high-pass noise masking. Annuls of Otology. Rhinology and Laryngology 88 (Suppl. 57), 1-20.

Gorga, M. P., Beauchaine K. A., \& Reiland J. K. (1987). Comparison of onset and steady-state response of hearing aids: Implications for use of the auditory brainstem response in the selection of hearing aids. Journal of Speech and Hearing Research, 30, 130-136.

Hall, J. W., \& Ruth, R. A. (1985). Acoustic reflexes and Auditory evoked responses in hearing aid evaluations.Seminars in Hearing, 6 (3), 251-277.

Hecox, K. E. (1983). Role of Auditory Brain Stem Responses in the selection of hearing Aids. Ear and Hearing, 4 (1), 51-55.

Hecox, K. E., Breuninger, C., \& Krebs, D. (1975). Brainstem evoked responses obtained from hearing-Aided adults. Jeurnal of the Acoustical Society of America, 57, 563.

Jerger, J., Hayes, D. , \& Jordan. (1980). Clinical experience with auditory brainstem response in pediatric assessment. Ear and Hearing. 1, 19-23. 
Kiessling, J. (1982). Hearing aid selection by brainstem audiometry.

Scandinavian Audiology, 11, 269-275.

Kileny, P.P. (1982). Auditory brainstem responses as indicators of hearing aid performance. Annals of Otology.Rhinology Laryngology, 21, 61-64.

Kodera, K., Yamana, H., Yamana, O., \& Suzuki, J. (1977). Brainstem response audiometry at speech frequencies. Audiology, 16, 469-479.

Mahoney, T. M. (1985). Auditory Brainstem Response Hearing Aid Applications. In J.T. Jacobson (Ed.), The Auditory Brainstem Response_(pp. 349-370). San Diego: College-Hill Press.

McPherson, D. L., \& Clark, N. E. (1983). ABR in hearing aid utilization: simulated deafness. Hearing instruments, 34 (11), 12,14-15, 66.

Mjoen, S. (1981). ABR in Pediatric audiology. Scandinavian Audiologx, 13 (Suppl), 141-146.

Mokotoff, B., \& Krebs D. F. (1976). Brainstem auditory-evoked responses with amplification. Paper presented at the 92nd meeting: Acoustical society of America. November.

Sanders, D. A. (1977) . Auditory Perception of Speech. An Introduction to Principles and Problems. Englewood Cliffs, NJ: Prentice-Hall.

Sanders, J.W. (1983). The slow Brainstem response in pure tone audiometry and hearing aid evaluation. Hearing Instruments, 34 (11), 16, 19-20.

Schiff, M., \& Sandlin, R. (1982). What can be done for the recruiting ear? Annuls of Otology. Rhinology and Lanyngology. September-October.

Skinner, M. W. (1988). Hearing Aid Evaluation. Englewood Cliffs, New Jersey: Prentice-Hall.

Stecker, M. (1982). Objective hearing aid fitting. Lanyngology. Rhinology and Otology, 61, 678-682.

Weber, B. A., Seitz, M.R., \& McCutcheon, M.J. (1981). Quantifying click stimuli in auditory brainstem response audiometry. Ear and Hearing, 2, 15-19. 


\section{APPENDIX A}

\section{ATTACK AND RELEASE TIME}

As stated in Oticon Corporation technical information sheet.

The time it takes the AGC to react to an incoming signal which is of greater amplitude than the kneepoint, is called the attack time.... The time it takes the AGC to quit functioning, when the signal again drops back to below the kneepoint, is called the recovery time...

In the case of this study, in order for an AGC circuit of a hearing aid to be activated, a signal must be of sufficient duration. for example, if a given hearing aid has an attack time of $25 \mathrm{~ms}$ and a transient signal lasts only $15 \mathrm{~ms}$, the signal itself is shorter in duration than the time it takes the hearing aids AGC circuit to be activated. Thus, theoretically the AGC circuit should not be activated by a signal that is shorter in duration than the time it takes to "turn on" (See Figure 1 for a graphic illustration of attack and release time). For more detailed information on attack and release time see Schweitzer (1979). 


\section{APPENDIX B}

\section{PEAK EQUIVALENT CALCULATION}

It is not possible to determine the output of a transient signals in the conventional fashion with a sound lever meter because of the brief amount of time the signal is present. In other words, the sound level meter is unable to react fast enough to measure the output of the transient signal. In order to determine the output in SPL of one cycle of a $3000 \mathrm{~Hz}$ tone, the amplitude of a continuous tone at $80 \mathrm{~dB}$ was determined, which equaled 2.2 volts peak to peak on the Iwatsu SS 5802 oscilloscope. Once the amplitude was known for the continuous tone at $80 \mathrm{~dB}$ (2.2 volts) it is then correct to say that an output of a transient signal of 2.2 volts is equivalent to $80 \mathrm{~dB}$, ie. $80 \mathrm{~dB}$ peak equivalent level. With the following formula it is possible to determine peak equivalent output values for any output.

$20 \times \log V_{1} / N_{0}=$ Peak equivalent output in SPL

For example, if the output of a transient is equal to 4.2 volts and the range of the sound level meter is set at $100 \mathrm{~dB}$, the calculation would go as follows.

$4.2 / 2.2=1.9091$

$\log$ of $1.9091=.2808266$

$.2808266 \times 20=5.6165322$

$5.6165+100$ (sound level meter reading) $=$ $105.6165 \mathrm{~dB}$ peak equivalent 